\title{
Revision of the Australian genus Alfredella Masner \& Huggert (Hymenoptera, Platygastridae, Sceliotrachelinae)
}

\author{
Zachary Lahey', Elijah Talamas², Lubomír Masner', Norman F. Johnson' \\ I Department of Evolution, Ecology, and Organismal Biology, The Ohio State University, 1315 Kinnear Road, \\ Columbus, Ohio 43212, USA 2 Florida State Collection of Arthropods, Florida Department of Agriculture \\ and Consumer Services, Division of Plant Industry, 1911 SW 34 th St. Gainesville, Florida 32608, USA \\ 3 Agriculture and Agri-Food Canada, K.W. Neatby Building, Ottawa, Ontario K1A OC6, Canada \\ Corresponding author: Zachary Lahey (lahey.18@osu.edu)
}

Academic editor:Matthew Yoder | Received 18 October 2020 | Accepted 23February 2021 | Published 23 December 2021

http://zoobank.org/6DB1F7F4-7402-4B7D-92C0-32F97800EF00

Citation: Lahey Z, Talamas E, Masner L, Johnson NF (2021) Revision of the Australian genus Alfredella Masner \& Huggert (Hymenoptera, Platygastridae, Sceliotrachelinae). In: Lahey Z, Talamas E (Eds) Advances in the Systematics of Platygastroidea III. Journal of Hymenoptera Research 87: 81-113. https://doi.org/10.3897/jhr.87.58368

\begin{abstract}
The genus Alfredella Masner \& Huggert is revised. Alfredella tasmanica Masner \& Huggert is redescribed, Al. teres (Buhl), comb. nov. is transferred to Alfredella from Amitus Haldeman, and Al. auriel Lahey, sp. nov. (New South Wales, Tasmania) and Al. mephisto Lahey, sp. nov. (Western Australia) are described as new. The genus Masnerium Polaszek, syn. nov. is treated as a junior synonym of Amitus, and its type species, M. wellsae Polaszek, is transferred to Amitus as Am. wellsae (Polaszek), comb. nov. The relationship between Alfredella and morphologically similar genera is discussed, and a key is provided to distinguish between Aleyroctonus Masner \& Huggert, Alfredella, and Amitus.
\end{abstract}

\section{Keywords}

Aleyroctonus, Amitus, endemic, Platygastroidea, Tasmania, taxonomy

\section{Introduction}

The subfamily Sceliotrachelinae contains a diverse assemblage of genera, most of which contain a small number of described species. Sceliotracheline wasps are minute in size, infrequently collected, and are most diverse in regions where they have been studied

Copyright Zachary Lahey et al. This is an open access article distributed under the terms of the Creative Commons Attribution License (CC BY 4.0), which permits unrestricted use, distribution, and reproduction in any medium, provided the original author and source are credited. 
the least. Masner and Huggert (1989) made a significant contribution to the study of these wasps in their seminal treatise of the subfamily and described 13 new monotypic genera, most of which are known only from the Southern Hemisphere. In particular, the landmasses that Australasia comprises (Australia, Melanesia, New Zealand, and Tasmania) are major centers of platygastrid diversity (Masner and Huggert 1989). Nineteen of the 28 described genera of Sceliotrachelinae are found throughout this region, eight of which are endemic to either Australia or New Zealand.

This research is conducted as part of an effort to revise the fauna of Sceliotrachelinae, with priority given to monotypic genera (Talamas and Masner 2016; Lahey et al. 2019b, c). Our purpose is to revise the species-level taxonomy of Alfredella Masner \& Huggert, update its generic concept, and compare the genus to putative closely related taxa. Masner and Huggert (1989) considered Amitus Haldeman to be the sister taxon to Alfredella, a relationship corroborated by a recent phylogenomic analysis of Platygastroidea based on ultraconserved elements (Blaimer et al., unpublished data). Both genera are extremely similar morphologically, and we compared specimens of the two genera to ensure the validity of Alfredella when developing the generic key. During this process, Amitus specimens from around the world were examined, along with new material of the monotypic Masnerium Polaszek.

The contributions of the authors are as follows: Z. Lahey: character definition and coding, generic concept development, key development, manuscript preparation, species concept development; E. Talamas: character definition, imaging, manuscript preparation; L. Masner: provision of specimens; and N.F. Johnson: project coordination, manuscript preparation.

\section{Materials and methods}

The numbers prefixed with "OSUC", "USNMENT", and "ZMUC" are unique identifiers for the individual specimens. Details of the data associated with these specimens may be accessed at https://mbd-db.osu.edu/ by entering the unique specimen identifier (e.g., OSUC 666417) in the form (note the blank space after some acronyms).

The following terms and abbreviations are used to describe the morphological structures discussed in the text - sensillar formula of clavomeres: distribution of papillary sensilla (PS) on the ventral clavomeres of the female (Yang et al. 2016), with the segment interval followed by the number of PS per segment (e.g., A10-A8/1-22) (Bin 1981); LOL: lateral ocellar line, shortest distance between the outer margins of the lateral and median ocelli (Masner 1980); OD: ocellar diameter, greatest width of each ocellus; OOL: ocular ocellar line, shortest distance between the inner orbit and outer margin of the lateral ocellus (Masner 1980); POL: posterior ocellar line, shortest distance between the inner margins of the lateral ocelli (Masner 1980); T1, T2, ... T6: metasomal tergite 1, 2, .. 6; S1, S2, .. S6: metasomal sternite 1, 2, . 6. Morphological terminology follows Masner and Huggert (1989), Mikó et al. (2007), and Lahey et al. $(2019 \mathrm{a}-\mathrm{c})$. Morphological terms were matched to concepts in the 
Hymenoptera Anatomy Ontology (Yoder et al. 2010) using the text analyzer function. A table of morphological terms and URI links is provided in Suppl. material 1.

Morphological character matrices and taxonomic descriptions were generated with vSysLab (https://vsyslab.osu.edu/), a web application that utilizes specimen data from the Hymenoptera Online Database (https://mbd-db.osu.edu/). Morphological characters are in the format of character: character state. Multistate characters are separated by a semicolon (e.g., number of clavomeres: $4 ; 5$ ).

The point map of Alfredella species distributions was created with SimpleMappr (Shorthouse 2010). Nomenclature of the bio- and ecoregions of Australia inhabited by Alfredella species follows that used in the Interim Biogeographic Regionalisation for Australia version 7 (https://www.environment.gov.au/land/nrs/science/ibra/australiasbioregions-maps) (Thackway and Cresswell 1995).

Photographs of card- or point-mounted insects were captured using a Macroscopic Solutions Macropod Micro Kit, with optical slices rendered in Helicon Focus. Image stacks were processed with CombineZP to produce single montage images, which were subsequently imported into Adobe Photoshop CC to correct for brightness and contrast. Most scanning electron micrographs were taken with a Phenom XL G2 Desktop Scanning Electron Microscope, using a eucentric stage and Phenom ProSuite Software. The scanning electron micrographs of Amitus (Figs 57-59, 61) were taken following the methods of Talamas et al. (2016).

\section{Collections}

This work is based on specimens deposited in the following repositories:
ANIC Australian National Insect Collection, Canberra, ACT, Australia
CNCI Canadian National Collection of Insects, Ottawa, Ontario, Canada
NHMUK Natural History Museum, London, United Kingdom
OSUC C.A. Triplehorn Collection, The Ohio State University, Columbus, Ohio, USA

USNM Smithsonian National Museum of Natural History, Washington, DC, USA ZMUC Zoological Museum, Natural History Museum of Denmark, University of Copenhagen, Copenhagen, Denmark

\section{Abbreviations and characters annotated in the figures}

$\begin{array}{ll}\text { ac } & \text { acetabular carina (Fig. 58) } \\
\text { afp } & \text { anterior mesofurcal pit (Figs 58, 60) } \\
\text { als } & \text { anterolateral striae on T2 (Figs 3, 50, 61) } \\
\text { amp } & \text { anterior mesosternal pits (Figs 58, 60) } \\
\text { apT2 } & \text { anteromedial pits on T2 (Fig. 61) } \\
\text { atp } & \text { anterior tentorial pit (Fig. 59) } \\
\text { auc } & \text { axillular carina (Figs 2, 61-63) } \\
\text { axu } & \text { axillula (Figs 61, 62) }\end{array}$




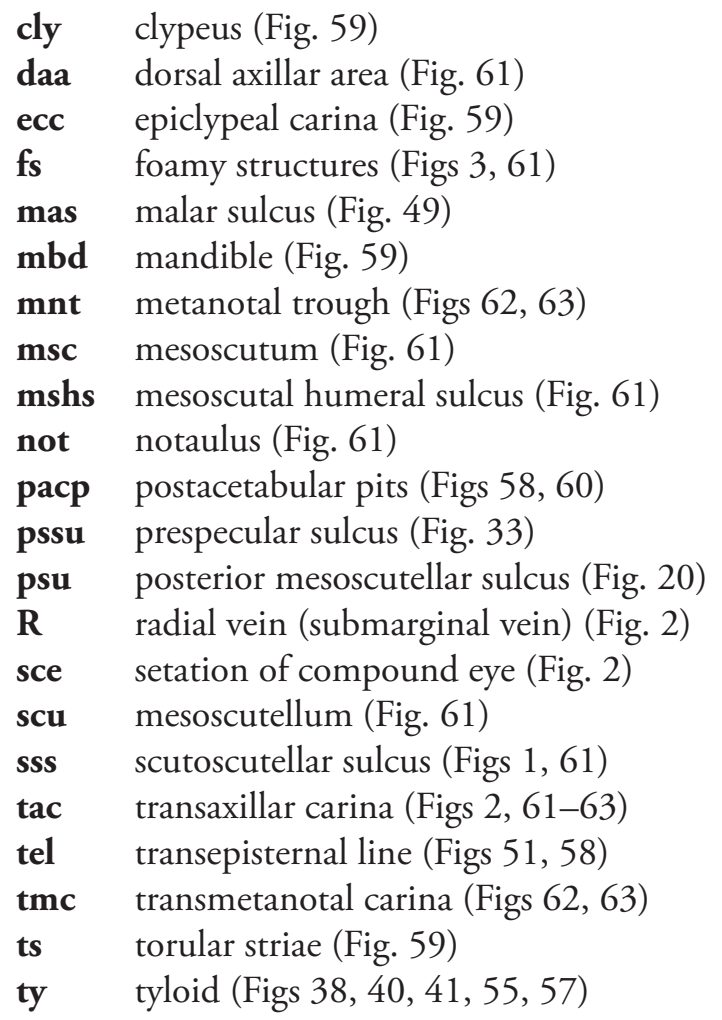

\section{Character discussion}

\section{Anterolateral striae on $\mathrm{T} 2$}

Alfredella and Amitus have striae that radiate from the anterior margin of T2 as well as the margins of the anteromedial pits (Figs 3, 50, 61). This character is particularly subtle in Alfredella relative to Amitus and requires the anterior margin of T2 to be free of obstructions such as the wings, hind legs, and detritus. Another Australian genus, Oligomerella Masner \& Huggert, also possesses striations on T2; however, this genus has a distinct malar sulcus (Fig. 49) and the 3-merous clava is massive relative to A3A7. We provide images of this exceptionally rare genus for the first time (Figs 46-49).

\section{Claval formula}

The antennal clava of Alfredella is 4- or 5-merous, with a papillary sensillar formula of 1-2-2-1 (Al. auriel), 1-2-2-1-1 (Al. teres), or 1-2-2-2-1 (Al. auriel, Al. mephisto, Al. tasmanica). Identifying specimens based on this character alone can be challenging and is best performed when examining the antennae ventrally or at an oblique angle. A small drop of exudate can usually be seen at the tip of each papillary sensillum, which serves as a good indicator of their presence (arrows on Fig. 30). 


\section{Shape of clypeus}

The shape of the ventral margin of the clypeus differs between species of Alfredella. In Al. tasmanica, the ventral clypeal margin is rounded (Fig. 44), whereas it is slightly more acuminate in Al. mephisto (Fig. 43). The clypeus is distinctly acuminate in Al. auriel and $A l$. teres; however, these two taxa differ by the setation of the clypeal area: sparse in Al. auriel (Fig. 42) and dense in Al. teres (Fig. 43).

\section{Tyloid}

Males of three of the four Alfredella species possess a noticeable tyloid on A4. The shape of the tyloid is plate-like in Al. auriel (Fig. 38) and Al. teres (Fig. 41), a potential synapomorphy that supports Alfredella and Amitus as sister groups. The shape of the tyloid is less clear in Al. tasmanica: its presence is indicated by a ventral ridge that extends most of the length of A4 (Fig. 40), but we were not able to acquire images that completely show this character. A tyloid was not observed on A4 of Al. mephisto (Fig. 39), most likely due to the accumulation of detritus on the only specimen available for scanning electron microscopy.

\section{Key to Aleyroctonus, Alfredella, and Amitus}

$1 \quad$ Tubular R vein of fore wing absent (Fig. 1); epiclypeal carina present (Fig. 59); transaxillar and axillular carinae fused (Figs 1, 61, 62); mesopleuron without prespecular sulcus (Fig. 51)

Amitus Haldeman

- $\quad$ Tubular $\mathrm{R}$ vein of fore wing present (Fig. 2); transaxillar and axillular carinae separated (Figs 2, 63); mesopleuron with prespecular sulcus indicated dorsally (Fig. 33)

2 Propodeum without foamy structures (Fig. 2); anterolateral surface of T2 without longitudinal striae (Fig. 2); setation of compound eyes dense (Fig. 2) Aleyroctonus Masner \& Huggert

- $\quad$ Propodeum with foamy structures (Fig. 3); anterolateral surface of T2 with striae radiating from anteromedial pit (Fig. 3); setation of compound eyes short or not distinct (Fig. 3)

Alfredella Masner \& Huggert

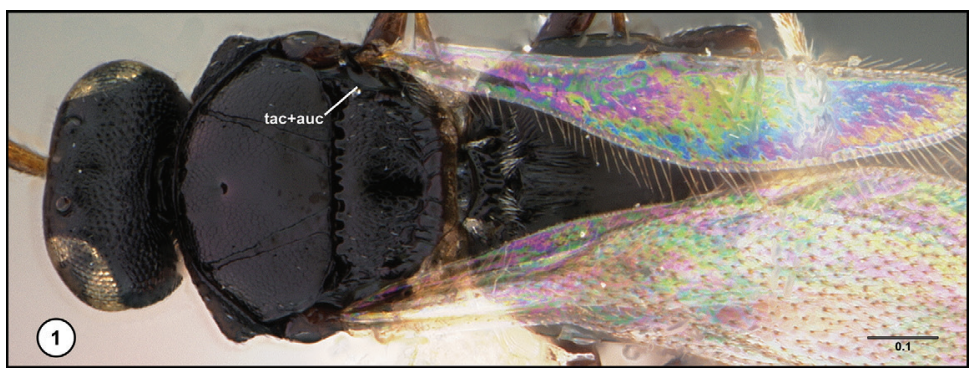

Figure I. Amitus granulosus MacGown \& Nebeker, female holotype (USNMENT01059097), head, mesosoma, metasoma, dorsal view. Scale bar in millimeters. 


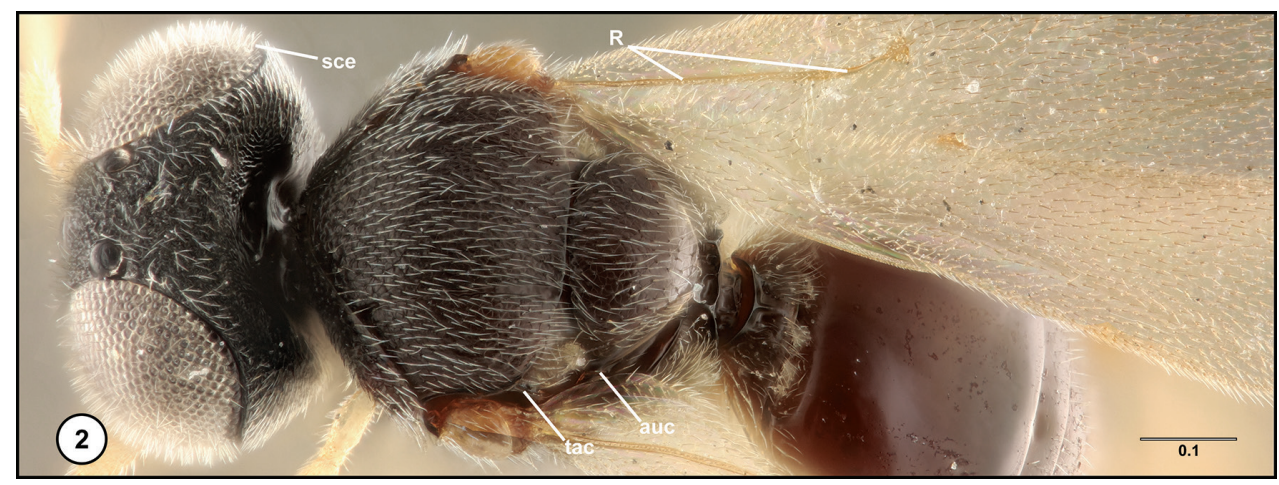

Figure 2. Aleyroctonus stanslyi Lahey \& Polaszek, female holotype (OSUC 697919), head, mesosoma, metasoma, dorsolateral view. Scale bar in millimeters.

\section{Key to species of Alfredella}

$1 \quad$ Notauli constricted posteriorly (Figs 7, 29); transepisternal line weakly arched (Figs 6, 28) ............................................................................ 2

- $\quad$ Notauli of even width throughout their length or absent (Figs 13, 20); transepisternal line strongly arched medially (Figs $12,16,22)$.......................3

2 Medial portion of mesoscutum and mesoscutellum setose (Figs 26, 29, 32); surface sculpture of mesoscutum and mesoscutellum composed of large reticulations (Figs 29, 32) .................................... Alfredella teres (Buhl)

- $\quad$ Medial portion of mesoscutum and mesoscutellum glabrous (Figs 5, 7, 10); surface sculpture of mesoscutum and mesoscutellum composed of fine reticulations (Figs 5, 7, 10)

Alfredella auriel Lahey, sp. nov.

3 Notauli parallel (Figs 18, 20, 25); posterior mesoscutellar sulcus absent medially (Fig. 20); ventral margin of clypeus rounded (Fig. 44)....

Alfredella tasmanica Masner \& Huggert

- Notauli converging posteriorly or notauli absent (Figs 11, 13); posterior mesoscutellar sulcus complete (Figs 11,13); ventral margin of clypeus acuminate (Fig. 43)

Alfredella mephisto Lahey, sp. nov.

\section{Taxonomy}

\section{Alfredella Masner \& Huggert}

Alfredella Masner \& Huggert, 1989: 39 (original description. Type: Alfredella tasmanica Masner \& Huggert, by monotypy and original designation); Vlug 1995: 10 (citation of type species); Lahey, Masner, and Johnson 2019: 69 (keyed).

Diagnosis. Alfredella is most similar to Aleyroctonus and Amitus. The combination of a tubular $\mathrm{R}$ vein in the fore wing (absent in Amitus) and anterolateral striae on T2 
(absent in Aleyroctonus) is enough to separate Alfredella from these genera. Moreover, Alfredella is one of only two platygastroid genera where the antennal clava is composed of both articulated (e.g., A6 and A7) and 'compact' (e.g., A8-A10) clavomeres. Additional diagnostic characters include the presence of malar striae, a 4- or 5-merous antennal clava, a distinct transepisternal line, and the presence of foamy structures on the propodeum.

Description. Head. Color of head: black. Shape of head in dorsal view: transverse. Occipital carina: present. Setation of compound eye: present, short. Hyperoccipital carina: absent. Occipital pit: absent. Paraocellar depressions: absent. Preocellar depressions: absent. Setation of occiput: present, short. Antennal scrobe: present. Frontal ledge: absent. Sculpture of frons immediately dorsal to toruli: concentrically rugose. Sculpture of upper frons: reticulate. Sculpture of vertex: reticulate. Malar striae: present. Malar sulcus: absent. Facial striae: absent. Epistomal sulcus: absent. Anteclypeus: undifferentiated from postclypeus. Orientation of mandiblar teeth: transverse. Mandibular dentition: bidentate. Number of maxillary palpomeres: 1. Number of labial palpomeres: 1. Number of antennomeres in female: 10 . Number of antennomeres in male: 9. Number of clavomeres: 4; 5. Sensillar formula of A10-A6: 1-2-2-1-0; 1-2-21-1; 1-2-2-2-1. Condition of A6: articulate. Condition of A7: articulate. Condition of $\mathrm{A} 10-\mathrm{A} 8$, female: fused, sutures present. Length of pedicel: approximately as long as $\mathrm{A} 3+\mathrm{A} 4$.

Mesosoma. Epomial carina: present ventrally. Pronotal shoulders: visible in dorsal view, not sharply angled. Sculpture of mesoscutum: reticulate. Anterior admedian line: present. Median mesoscutal line: absent. Notaulus: present. Parapsidal line: present. Mesoscutal humeral sulcus: present as a thin furrow. Netrion: present. Scutoscutellar sulcus: present as a deep, noncrenulate groove. Sculpture of mesoscutellum: reticulate. Shape of mesoscutellum: nearly hexagonal, widest medially. Setation of axillula: dense. Metascutellum: concealed by posterior margin of mesoscutellum. Prespecular sulcus: present. Transepisternal line: present, terminating in anterior and posterior pits. Mesopleural carina: absent. Metapleural carina: present. Metapleural sulcus: absent. Metapleural pit: present. Location of metapleural pit: at anterior margin of metapleuron. Paracoxal sulcus: absent. Setation of plical area: dense. Protibial spur: bifid. Tibial spur formula: 1-2-2. Tarsal formula: 5-5-5. Length of tarsal claws: equal. Foamy structures: present on lateral propodeal carinae and metapleural carina.

Metasoma. Number of visible terga, female: 6 . Number of visible terga, male: 8 . Number of visible sterna: at least 6 . Width of laterotergites: short. Sculpture of terga: T2 anterolaterally striate. Laterotergites: present. Laterosternites: absent. Sculpture of nucha: longitudinally foveolate. Shape of T1: transverse. Anterior pits on T2: present as transverse, setose depressions medially. Longest tergite: T2. Sculpture of S2: smooth except for longitudinal striation and reticulation surrounding felt field. Transverse felt field on anterior S2: present.

Wings. Color of wings: hyaline. Wing development: macropterous. Length of fore wing: exceeding apex of metasoma. Marginal cilia of fore wing: present. $\mathrm{R}$ of fore wing: present, tubular. Length of fore wing R: approximately $1 / 3$ length of fore wing. Shape of knob of R: truncate, not rounded. Cu of fore wing: nebulous. $\mathrm{M}$ of fore wing: 
nebulous. $\mathrm{M}+\mathrm{Cu}$ of fore wing: nebulous. Marginal cilia of hind wing: present. $\mathrm{R}$ of hind wing: present, tubular.

Distribution. Mainland Australia (Australian Capital Territory, New South Wales, Queensland, South Australia, Western Australia) and the island of Tasmania. The absence of specimens from Victoria is likely due to a lack of collecting.

\section{Species descriptions}

\section{Alfredella auriel Lahey, sp. nov.} http://zoobank.org/6A9392CE-6320-4FD7-84C9-FB052D7553BA Figs 3, 5-10, 34, 38, 42

Description. Setation of mandibles: present. Setation of clypeal area: sparse. Shape of clypeus: acuminate. Anterior tentorial pits: small. Facial and malar striae: present, dorsal striations confluent with concentric sculpture of antennal scrobe. Central keel: absent. Setation of interantennal area: extending to dorsal margin of toruli. Sculpture of frons: reticulate dorsally and along inner orbits, reticulations fading medially, supplanted by concentric striations of antennal scrobe, punctation present near ocelli. Position of lateral ocellus: approximately $1 \mathrm{OD}$ from inner margin of compound eye. Interocular space: $1.25 \times$ length of compound eye. Occiput directly anterior to anteromedial portion of occipital carina: granulate. Sculpture of occiput: reticulate; granulate. Color of antennomeres: yellow-orange; concolorous with legs. Number of papillary sensilla on A6: $0 ; 1$. Number of papillary sensilla on A7: 1. Glabrous patch on lateral propodeal area adjacent to spiracle: present. Shape of mesoscutellum in lateral view: flat. Shape of transepisternal line: weakly arched. Shape of mesoscutellum in dorsal view: pentagonal. Sculpture of posterior mesoscutellar sulcus: striate. Posterior mesoscutellar sulcus: complete. Setation of mesoscutum: absent posteromedially, dense lateral to notauli. Setation of mesoscutellum: present throughout. Path of notauli: converging posteriorly. Shape of notaulus: abruptly widening posteriorly. Setation of anteromedial T2: interrupted medially. Number of setae on lateral surface of T3: 3. Number of setae on

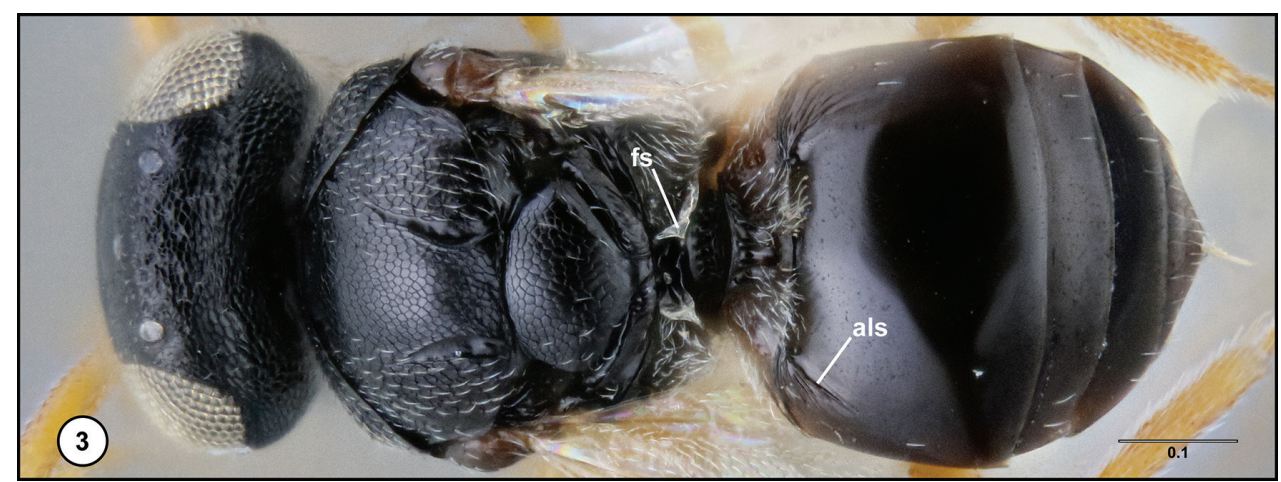

Figure 3. Alfredella auriel Lahey, female (USNMENT01197967), head, mesosoma, metasoma, dorsal view. Scale bar in millimeters. 


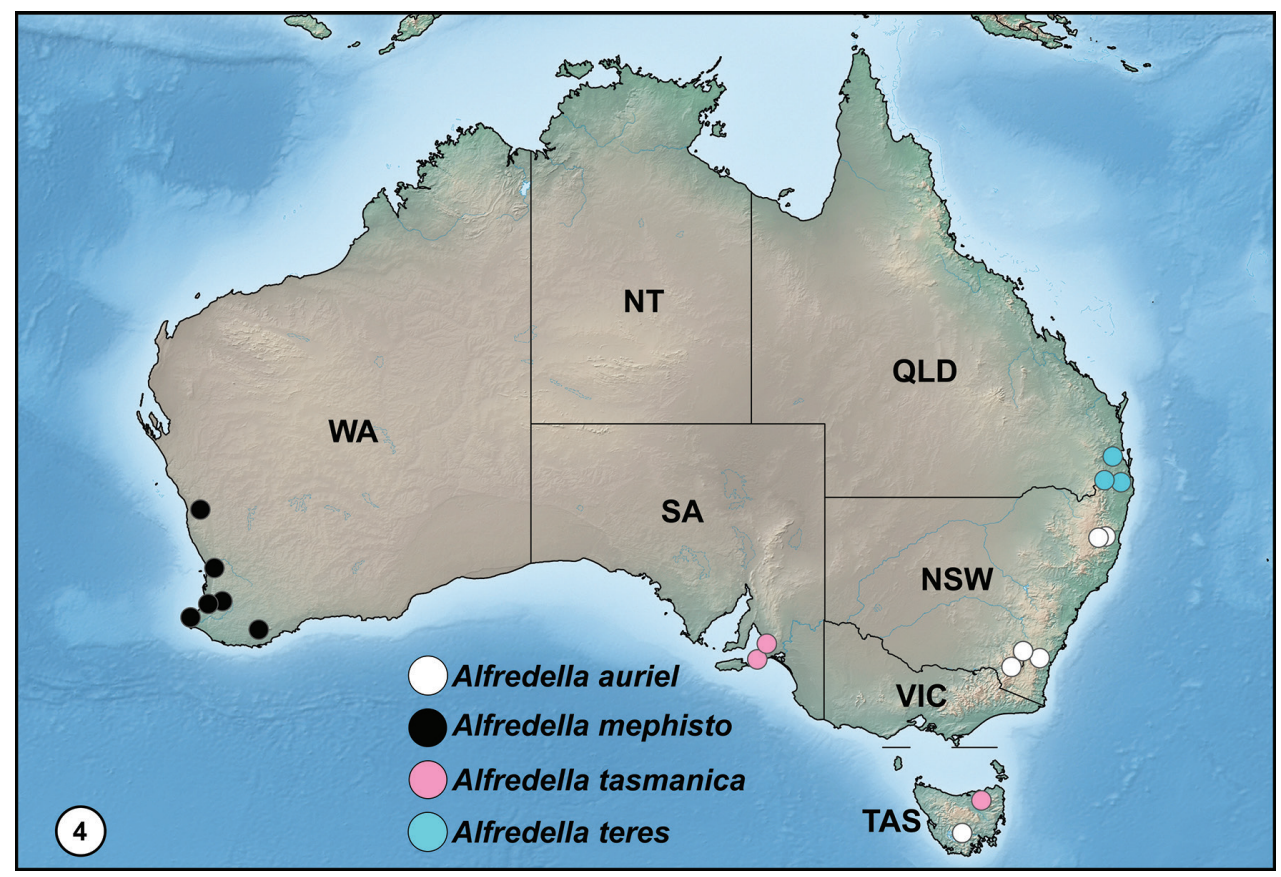

Figure 4. Distribution of Alfredella Masner \& Huggert across Australia. Multiple specimens collected from the same locality are indicated by a single circle. States and territories are abbreviated as follows: NSW (New South Wales), NT (Northern Territory), QLD (Queensland), SA (South Australia), TAS (Tasmania), VIC (Victoria), WA (Western Australia).

lateral surface of T4: 4. Number of setae on lateral surface of T5: 5. Felt field on S2: 0.5 as long as lt2. Setation of laterotergites: present on lt2-lt5. Setation of dorsal surface of hind coxa: absent medially. Color of coxae: yellow-orange.

Diagnosis. This species is easily recognized by the shape of the notauli, lack of setae on the mesoscutal midlobe, and sparsely setose clypeal area.

Distribution. New South Wales, Tasmania.

Inhabited ecoregions (bioregions). Temperate Broadleaf and Mixed Forests (South Eastern Queensland, South East Corner, South Eastern Highlands, Tasmanian Southern Ranges).

Etymology. Auriel is the Archangel of Hope from the Diablo video game franchise. The epithet is treated as a noun in apposition.

Material examined. Holotype, female: Australia: NSW, New England N. P., 1300-1500 m, Feb. 13,1984, L. Masner, s. s., OSUC 698019 (deposited in ANIC). Paratypes: Australia: 8 females, 6 males, OSUC 698007-698009, 698011-698012, 698014-698015, 698017-698018, 698020-698024 (CNCI). Additional material: Australia: 1 female, USNMENT01197967 (USNM).

Comments. While most female specimens in the type series have a 4-merous clava, we examined four specimens (OSUC 698007-698009, USNMENT01197967) from Kosciuszko National Park (New South Wales) with 5 clavomeres. We treat these specimens under Al. auriel given a lack of additional characters that would warrant new species status. 


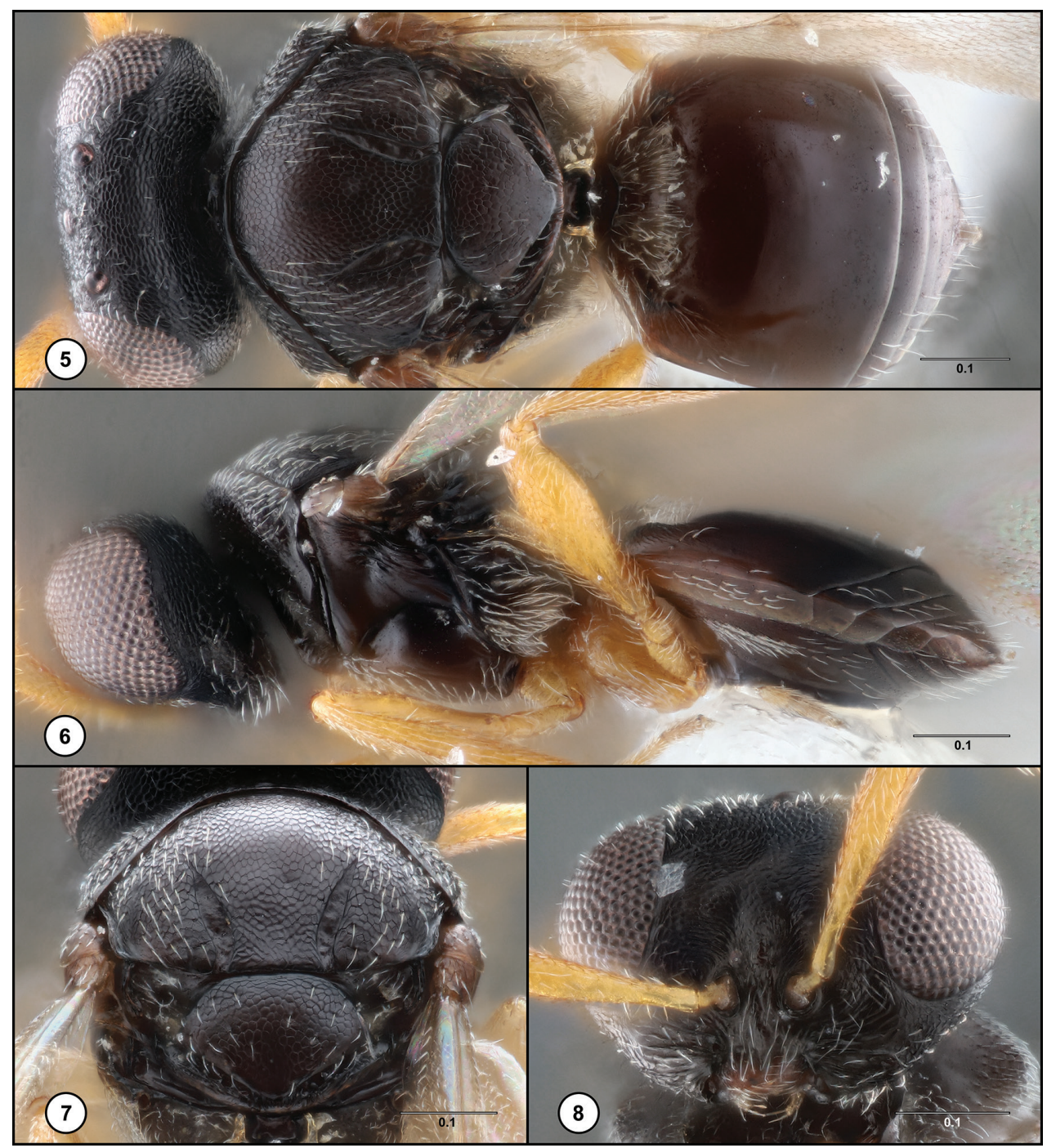

Figures 5-8. Alfredella auriel Lahey, female holotype (OSUC 698019) $\mathbf{5}$ head, mesosoma, metasoma, dorsal view $\mathbf{6}$ head, mesosoma, metasoma, lateral view $\mathbf{7}$ mesosoma, posterodorsal view $\mathbf{8}$ head, anterior view. Scale bars in millimeters.

\section{Alfredella mephisto Lahey, sp. nov.} http://zoobank.org/E4CC0A93-6144-45B7-95F1-09BD50D1588A Figs 11-16, 35, 39, 43

Description. Setation of mandibles: present. Setation of clypeal area: dense. Shape of clypeus: truncate. Anterior tentorial pits: large. Facial and malar striae: present, dorsal striations confluent with concentric sculpture of antennal scrobe. Central keel: present; absent. Setation of interantennal area: surpassing dorsal margin of toruli. Sculpture 


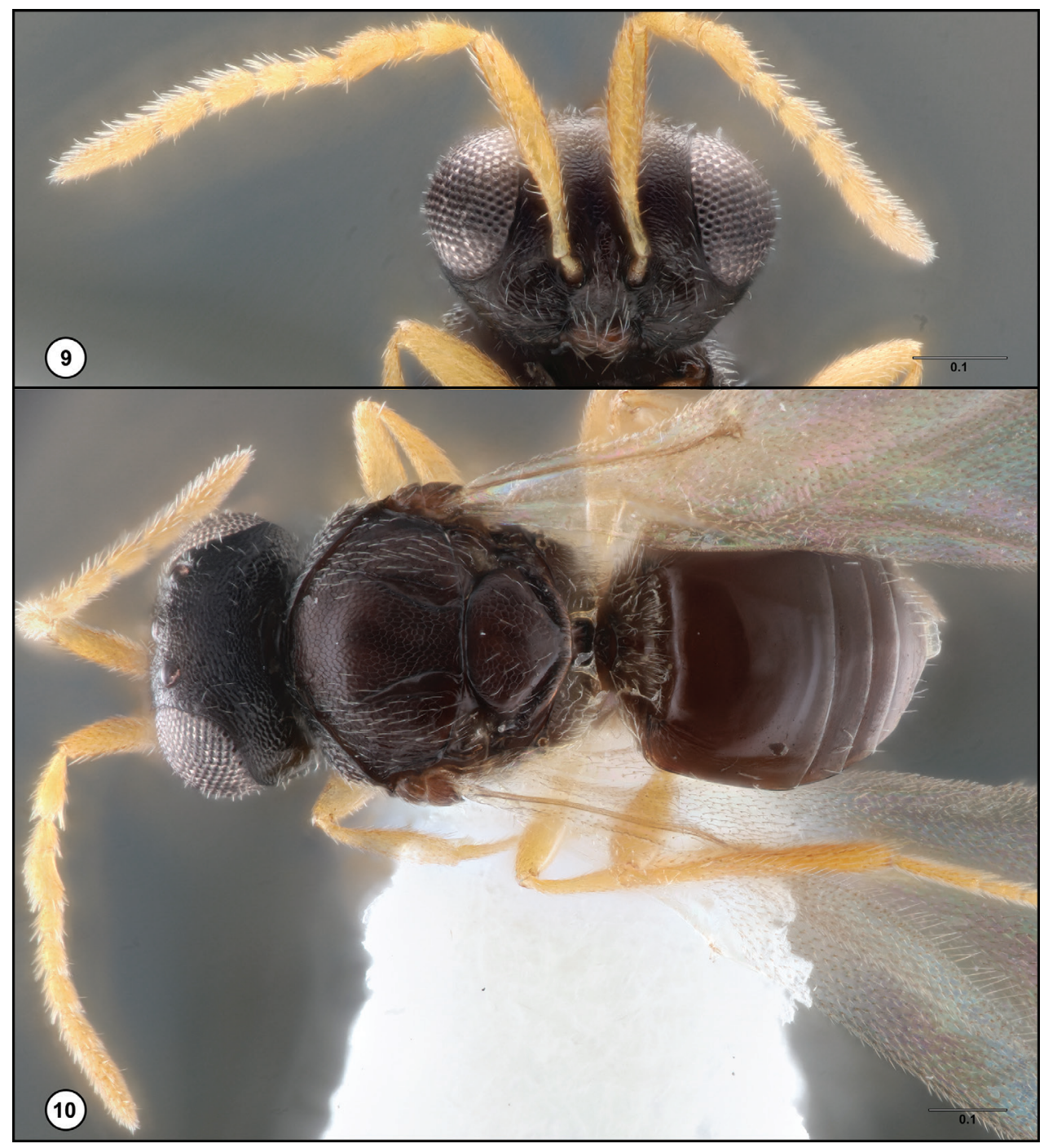

Figures 9, I0. Alfredella auriel Lahey, male paratype (OSUC 698020) 9 head, anterior view 10 head, mesosoma, metasoma, dorsal view. Scale bars in millimeters.

of frons: reticulate dorsally and along inner orbits, smooth medially, with weak concentric striations of antennal scrobe, punctation absent near ocelli. Position of lateral ocellus: less than $1 \mathrm{OD}$ from inner margin of compound eye. Interocular space: $1.25 \times$ length of compound eye. Occiput directly anterior to anteromedial portion of occipital carina: densely reticulate. Sculpture of occiput: densely reticulate. Color of antennomeres: brown-light brown; concolorous with legs. Number of papillary sensilla on A6: 1. Number of papillary sensilla on A7: 2. Glabrous patch on lateral propodeal area adjacent to spiracle: absent. Shape of mesoscutellum in lateral view: convex. Shape of transepisternal line: arched. Shape of mesoscutellum in dorsal view: oval, $2 \times$ wider 


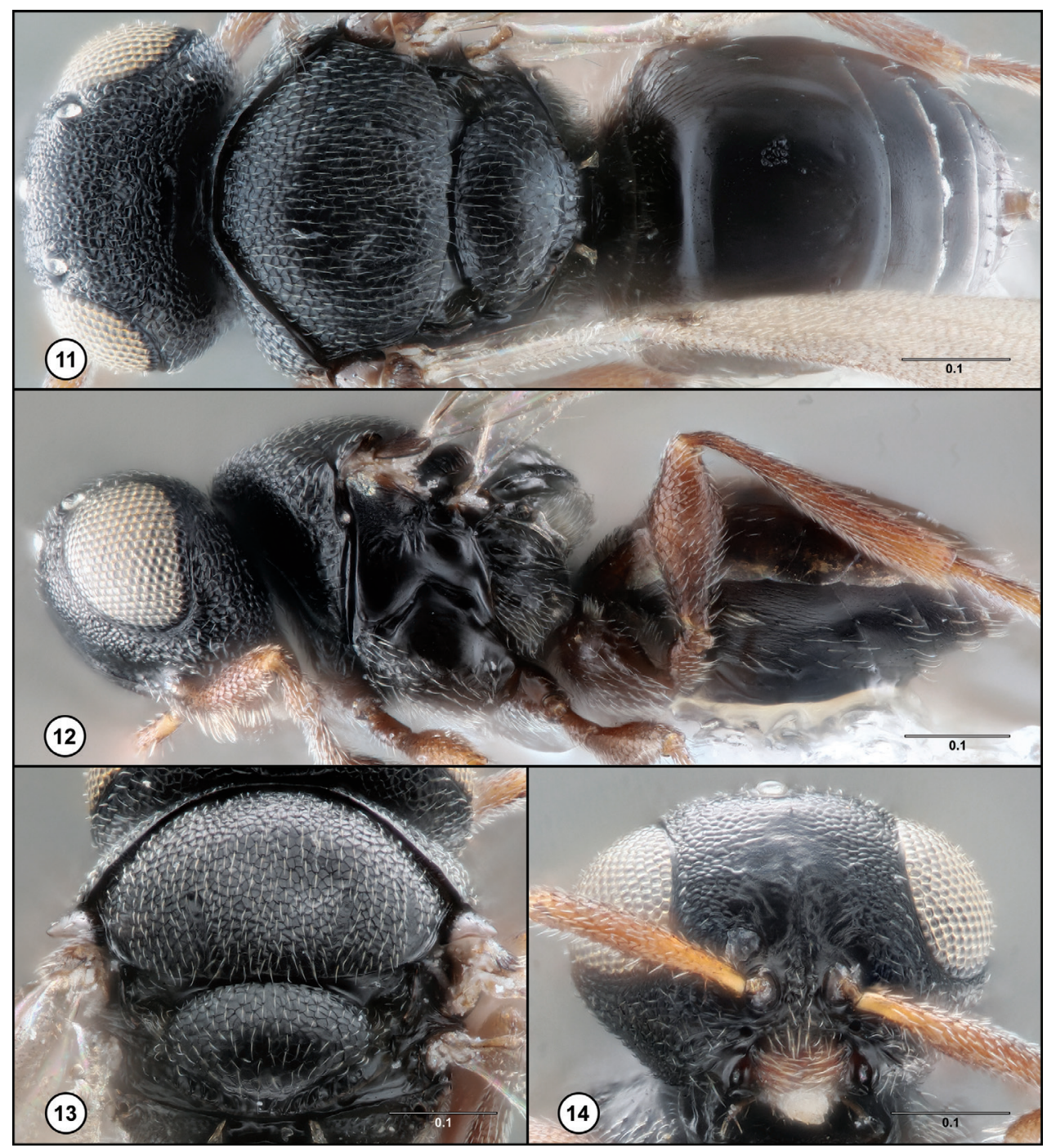

Figures I I-I4. Alfredella mephisto Lahey, female holotype (OSUC 697984) I I head, mesosoma, metasoma, dorsal view $\mathbf{I} \mathbf{2}$ head, mesosoma, metasoma, lateral view $\mathbf{I} \mathbf{3}$ mesosoma, posterodorsal view $\mathbf{I} \mathbf{4}$ head, anterior view. Scale bars in millimeters.

than long. Sculpture of posterior mesoscutellar sulcus: striate. Posterior mesoscutellar sulcus: complete, medial portion sometimes hidden by overhang of mesoscutellum. Setation of mesoscutum: present. Setation of mesoscutellum: present throughout. Path of notauli: subparallel; diverging anteriorly. Shape of notauli: narrowing posteriorly. Setation of anteromedial T2: contiguous. Number of setae on lateral surface of T3: 3 . Number of setae on lateral surface of T4: 3. Number of setae on lateral surface of T5: 6. Felt field on S2: approximately as long as lt2. Setation of laterotergites: present on 


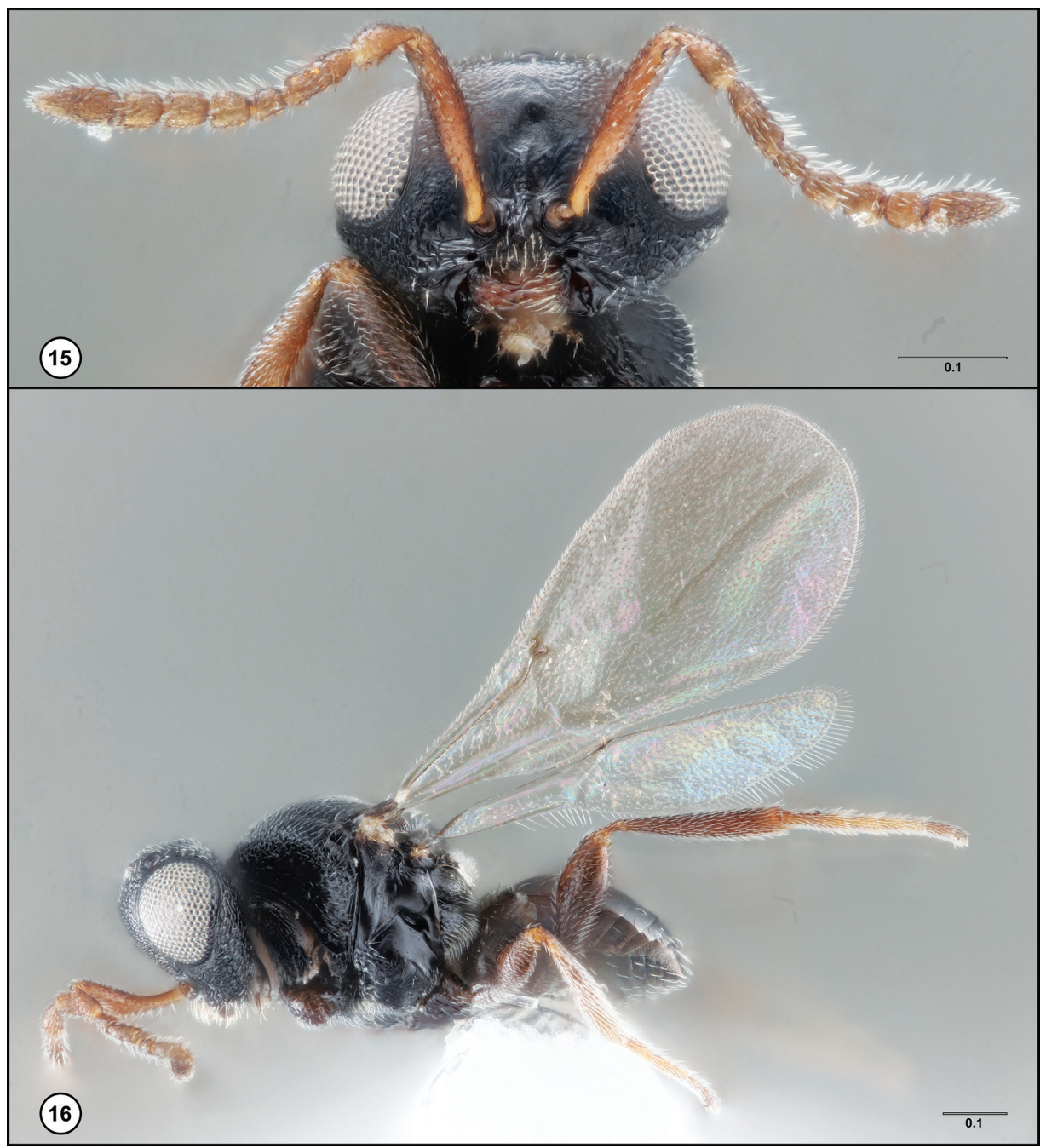

Figures 15, 16. Alfredella mephisto Lahey, male paratype (OSUC 697985) I5 head, anterior view 16 head, mesosoma, metasoma, lateral view. Scale bars in millimeters.

lt2. Setation of dorsal surface of hind coxa: absent medially. Color of coxae: brown; lighter than mesosoma.

Diagnosis. Alfredella mephisto is identifiable by the abbreviated notauli and complete posterior mesoscutellar sulcus.

Distribution. Western Australia.

Inhabited ecoregions (bioregions). Mediterranean Forests, Woodlands, and Scrub (Esperance Plains, Jarrah Forest, Swan Coastal Plain, Warren).

Etymology. Mephisto is one of the Prime Evils in the Diablo video game franchise. The epithet is treated as a noun in apposition. 


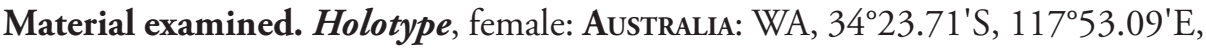
Stirling Range National Park, 22.XI.2002, J. George, OSUC 697984 (deposited in ANIC). Paratypes: Australia: 4 females, 4 males, OSUC 697985 (ANIC); OSUC 697986-697992 (CNCI).

Comments. Alfredella mephisto is the only species from Western Australia treated in this revision. We examined a single male of an undescribed species from the same state (OSUC 698016; collected near Yarragil Campground, Dwellingup) but have chosen not to describe it until additional material is collected.

\section{Alfredella tasmanica Masner \& Huggert}

Figs 17-25, 36, 40, 44

Alfredella tasmanica Masner \& Huggert, 1989: 40 (original description); Vlug 1995:

10 (cataloged, type information).

Description. Setation of mandibles: present. Setation of clypeal area: dense. Shape of clypeus: truncate. Anterior tentorial pits: large. Facial and malar striae: present, dorsal striations not confluent with concentric sculpture of antennal scrobe. Central keel: absent. Setation of interantennal area: surpassing dorsal margin of toruli. Sculpture of frons: reticulate throughout, weakly reticulate medially, punctation absent dorsally. Position of lateral ocellus: less than 1 OD from inner margin of compound eye. Interocular space: $1.25 \times$ length of compound eye. Occiput directly anterior to anteromedial portion of occipital carina: smooth to reticulate. Sculpture of occiput: densely reticulate; reticulate. Color of antennomeres: yellowbrown; concolorous with legs. Number of papillary sensilla on A6: 1. Number of papillary sensilla on A7: 2. Glabrous patch on lateral propodeal area adjacent to spiracle: absent. Shape of mesoscutellum in lateral view: convex. Shape of transepisternal line: arched. Shape of mesoscutellum in dorsal view: oval, $2 \times$ wider than long. Sculpture of posterior mesoscutellar sulcus: laterally striate, smooth medially. Posterior mesoscutellar sulcus: incomplete medially. Setation of mesoscutum: present. Setation of mesoscutellum: present throughout. Path of notauli: subparallel. Shape of notauli: same width throughout. Setation of anteromedial T2: contiguous. Number of setae on lateral surface of T3: 2; 3. Number of setae on lateral surface of T4: 4. Number of setae on lateral surface of T5: 6. Felt field on S2: approximately as long as lt2. Setation of laterotergites: present on lt2. Setation of dorsal surface of hind coxa: sparse. Color of coxae: brown; concolorous with mesosoma.

Diagnosis. Alfredella tasmanica differs from its congeners by the abbreviated, parallel notauli, incomplete posterior mesoscutellar sulcus, and nearly truncate ventral clypeal margin.

Distribution. Australian Capital Territory, South Australia, Tasmania. 


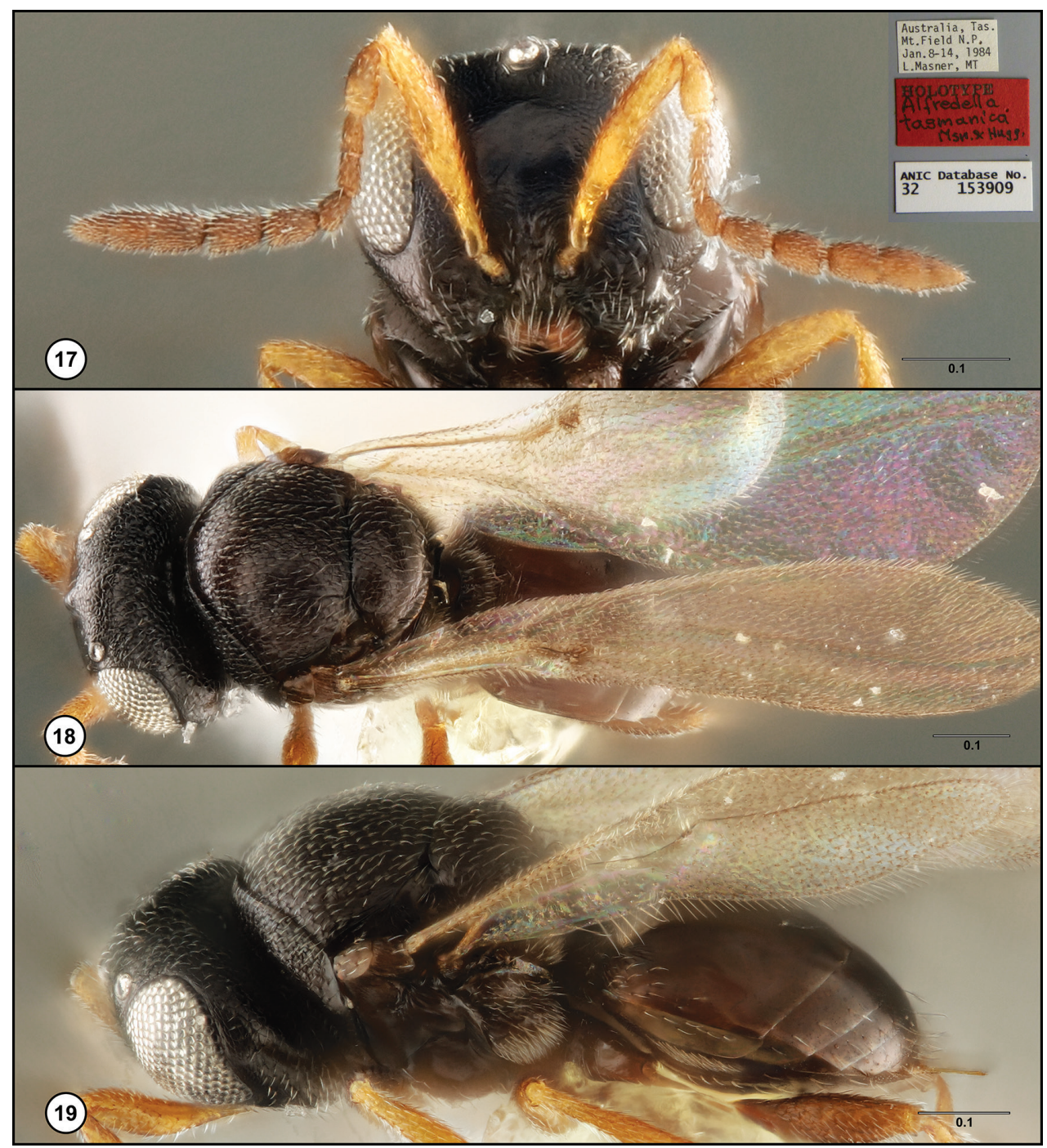

Figures 17-1 9. Alfredella tasmanica Masner \& Huggert, female holotype (ANIC 32-153909) I 7 head, anterior view (inset: specimen labels) $\mathbf{1 8}$ head, mesosoma, metasoma, dorsal view $\mathbf{1 9}$ head, mesosoma, metasoma, dorsolateral view. Scale bars in millimeters.

Inhabited ecoregions (bioregions). Deserts and Xeric Shrublands (Flinders Lofty Block); Temperate Broadleaf and Mixed Forests (Kanmantoo, Ben Lomond, Tasmanian Southern Ranges).

Material examined. Holotype, female: Australia: Tasmania, Mt. Field N.P., Jan. 8-14, 1984, L. Masner, MT, ANIC Database No. 32153909 (deposited in ANIC). Paratypes: Australia: 3 females, 1 male, OSUC $697975-697978$ (CNCI). Other material: Australia: 5 females, OSUC 697979-697983 (CNCI). 


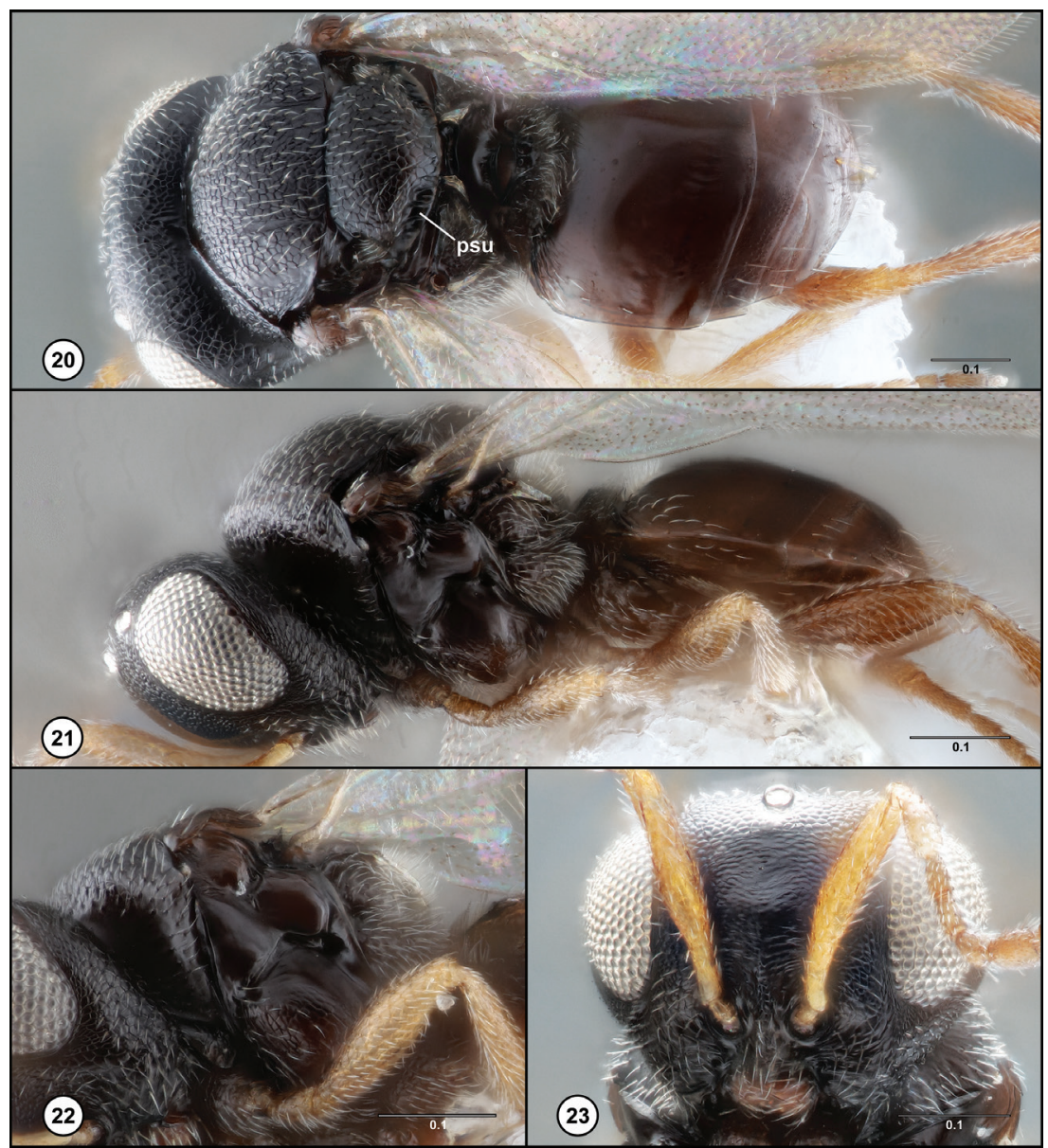

Figures 20-23. Alfredella tasmanica Masner \& Huggert, female paratype (OSUC 697975) 20 head, mesosoma, metasoma, posterodorsal view $\mathbf{2} \mathbf{I}$ head, mesosoma, metasoma, lateral view $\mathbf{2 2}$ mesopleuron, ventrolateral view $\mathbf{2 3}$ head, anterior view. Scale bars in millimeters.

Comments. The distribution of this species is expanded to include the Fleurieu Peninsula and Waite Arboretum of South Australia and Black Mountain of Australian Capital Territory. Alfredella tasmanica likely has a wide distribution across southern Australia, and its absence from Victoria is probably due to a lack of collecting in that region.

\section{Alfredella teres (Buhl), comb. nov.}

Figs $26-33,37,41,45$

Amitus teres Buhl, 2014: 428 (original description, diagnosis).

Description. Setation of mandibles: present. Setation of clypeal area: dense. Shape of clypeus: acuminate. Anterior tentorial pits: large. Facial and malar striae: present, 


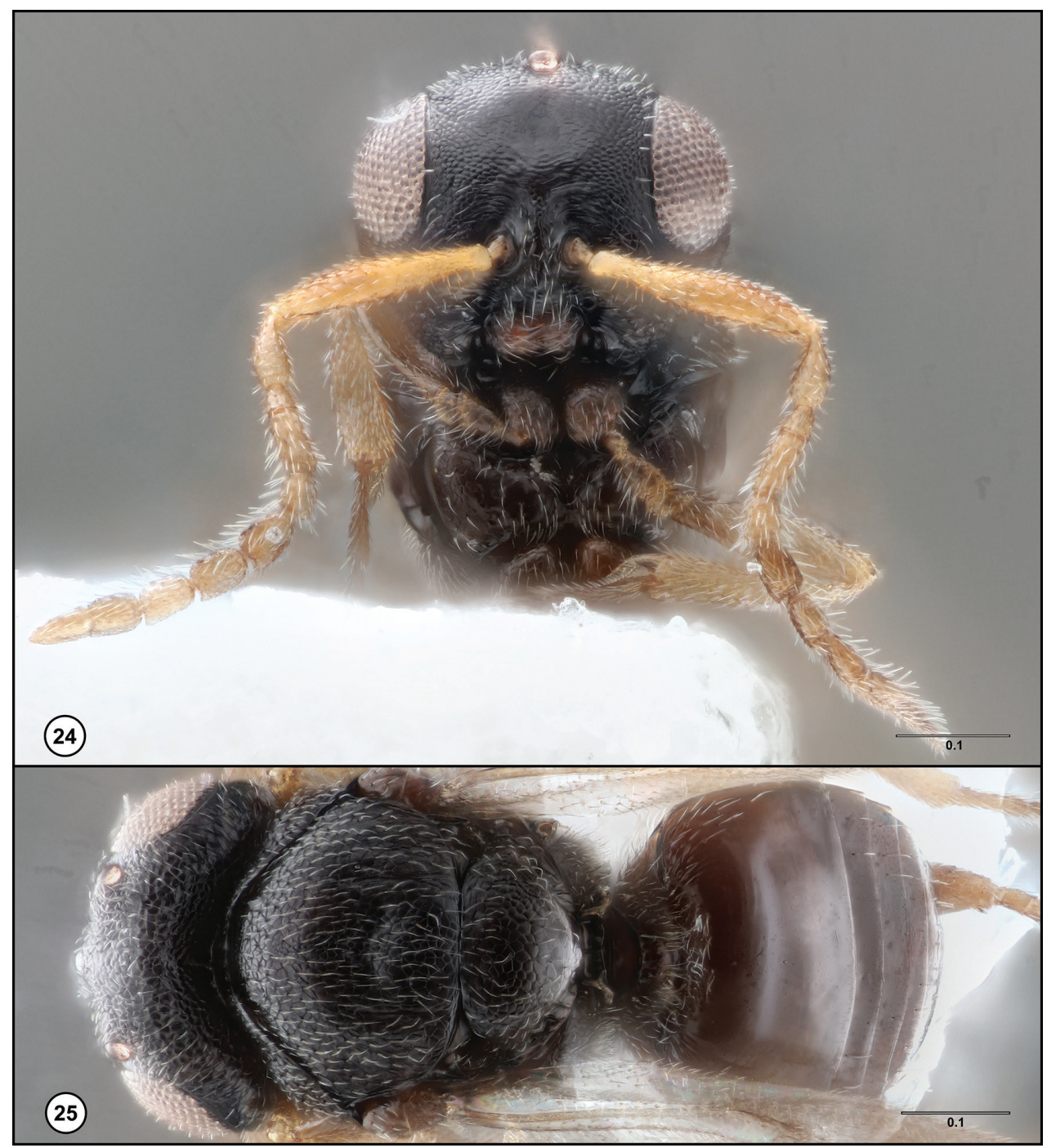

Figures 24, 25. Alfredella tasmanica Masner \& Huggert, male paratype (OSUC 697978) 24 head, anterior view $\mathbf{2 5}$ head, mesosoma, metasoma, dorsal view. Scale bars in millimeters.

dorsal striations confluent with concentric sculpture of antennal scrobe. Central keel: present. Setation of interantennal area: extending to dorsal margin of toruli. Sculpture of frons: reticulate dorsally and along inner orbits, reticulations fading medially, supplanted by concentric striations of antennal scrobe ventrally, completely smooth dorsally, punctation present near ocelli. Position of lateral ocellus: less than 1 OD from inner margin of compound eye. Interocular space: $1.25 \times$ length of compound eye. Occiput directly anterior to anteromedial portion of occipital carina: densely reticulate. Sculpture of occiput: densely reticulate. Color of antennomeres: yellow-orange; concolorous with legs. Number of papillary sensilla on A6: 1. Number of papillary sensilla on A7: 1. Glabrous patch on lateral propodeal area adjacent to spiracle: present. Shape 


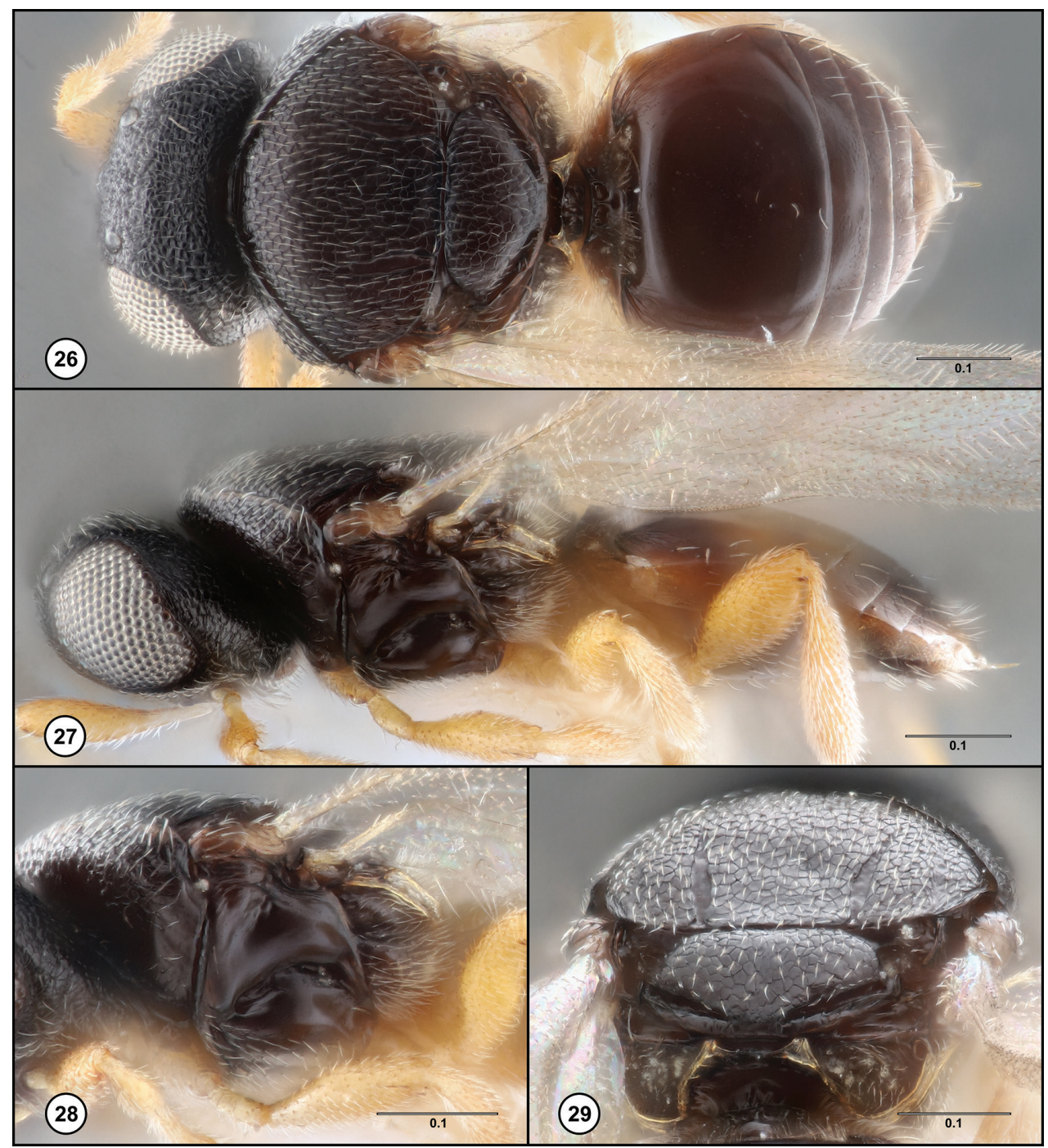

Figures 26-29. Alfredella teres (Buhl), female (OSUC 697995) 26 head, mesosoma, metasoma, dorsal view $\mathbf{2 7}$ head, mesosoma, metasoma, lateral view $\mathbf{2 8}$ mesopleuron, lateral view $\mathbf{2 9}$ mesosoma, posterodorsal view. Scale bars in millimeters.

of mesoscutellum in lateral view: flat. Shape of transepisternal line: straight. Shape of mesoscutellum in dorsal view: pentagonal. Sculpture of posterior mesoscutellar sulcus: weakly striate. Posterior mesoscutellar sulcus: incomplete medially. Setation of mesoscutum: present. Setation of mesoscutellum: present throughout. Path of notauli: converging posteriorly. Shape of notauli: gradually widening posteriorly. Setation of anteromedial T2: interrupted medially. Number of setae on lateral surface of T3: 3; 4; 5 . Number of setae on lateral surface of T4: $3 ; 4 ; 5$. Number of setae on lateral surface of T5: 6. Felt field on S2: approximately as long as lt2. Setation of laterotergites: present on lt2. Setation of dorsal surface of hind coxa: absent medially. Color of coxae: orange. 


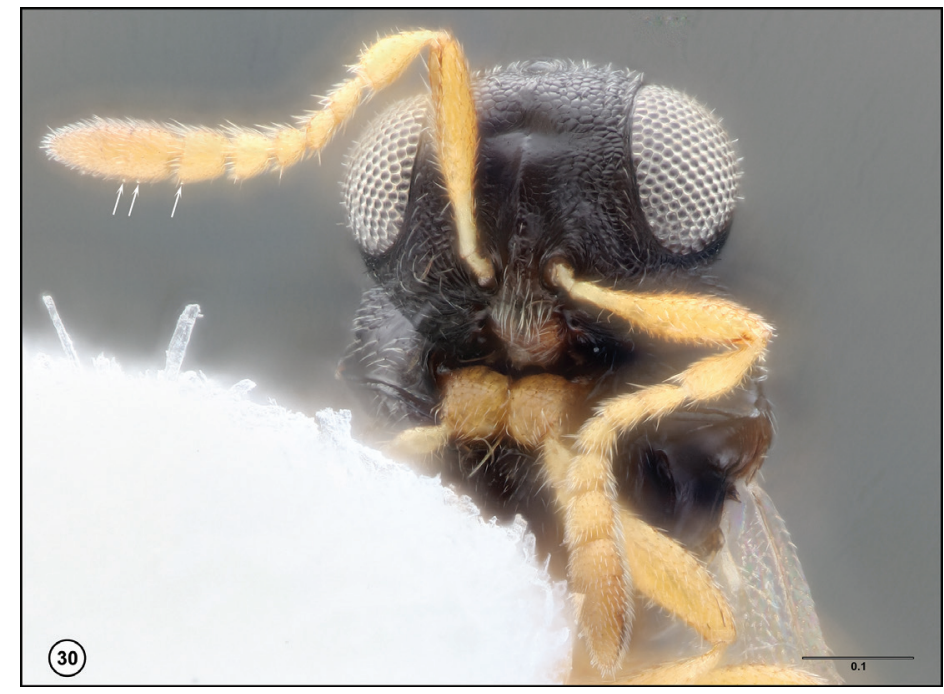

Figure 30. Alfredella teres (Buhl), female (OSUC 697995), head, anterior view. Scale bar in millimeters.

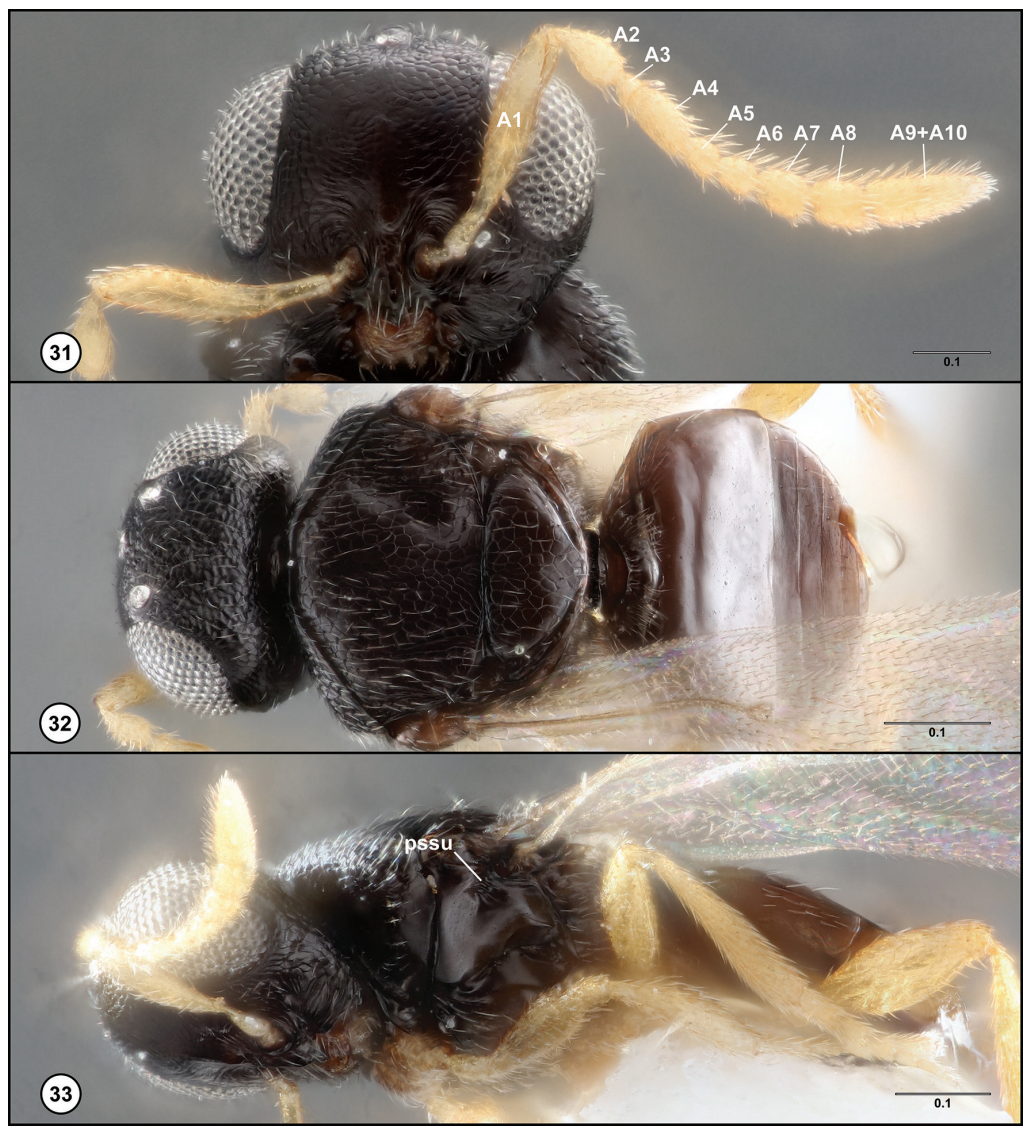

Figures 3 I-33. Alfredella teres (Buhl), male (OSUC 697999) $\mathbf{3} \mathbf{I}$ head, anterior view $\mathbf{3 2}$ head, mesosoma, metasoma, dorsal view $\mathbf{3} 3$ head, mesosoma, metasoma, ventrolateral view. Scale bars in millimeters. 


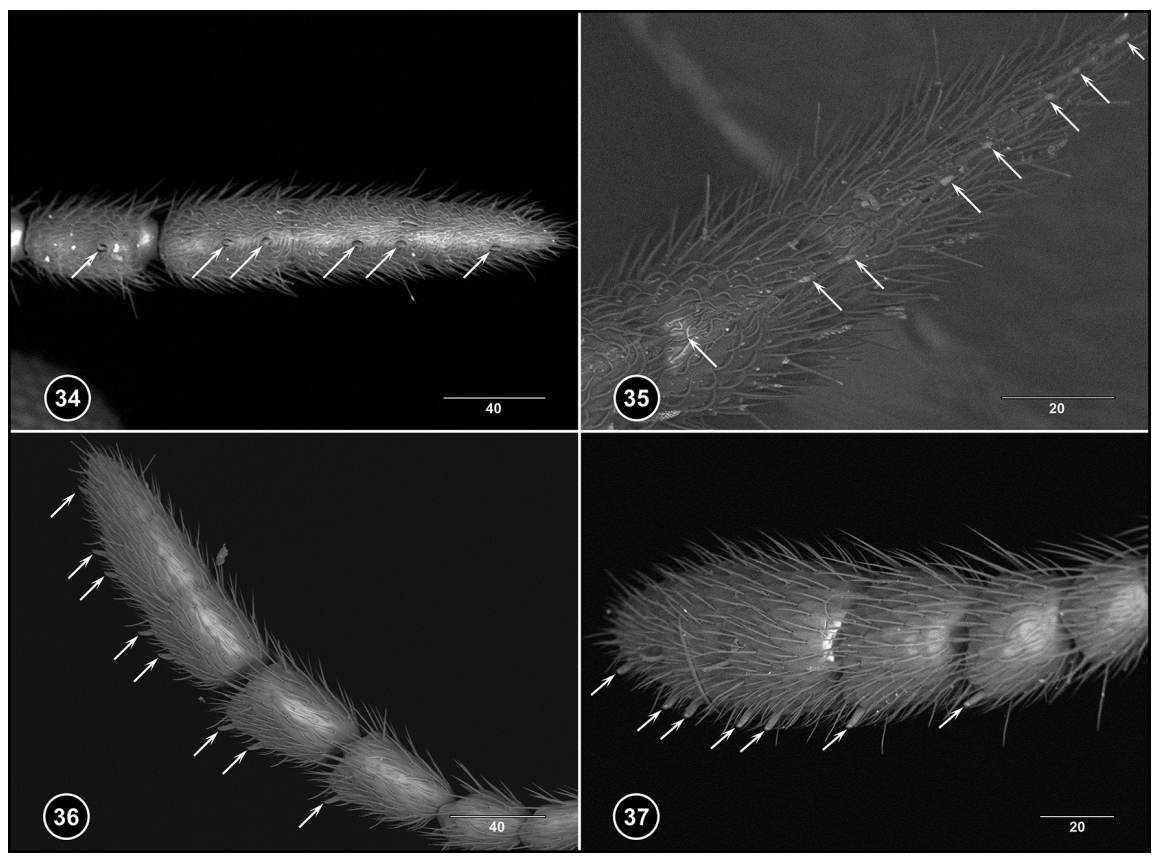

Figures 34-37. Clava and claval formulae of female Alfredella Masner \& Huggert 34 Alfredella auriel Lahey, holotype (OSUC 698019), ventral view 35 Alfredella mephisto Lahey, holotype (OSUC 697984), ventral view 36 Alfredella tasmanica Masner \& Huggert, paratype (OSUC 697975), lateral view 37 Alfredella teres (Buhl), (OSUC 697995), posterolateral view. Each arrow indicates a papillary sensillum. Scale bars in micrometers.

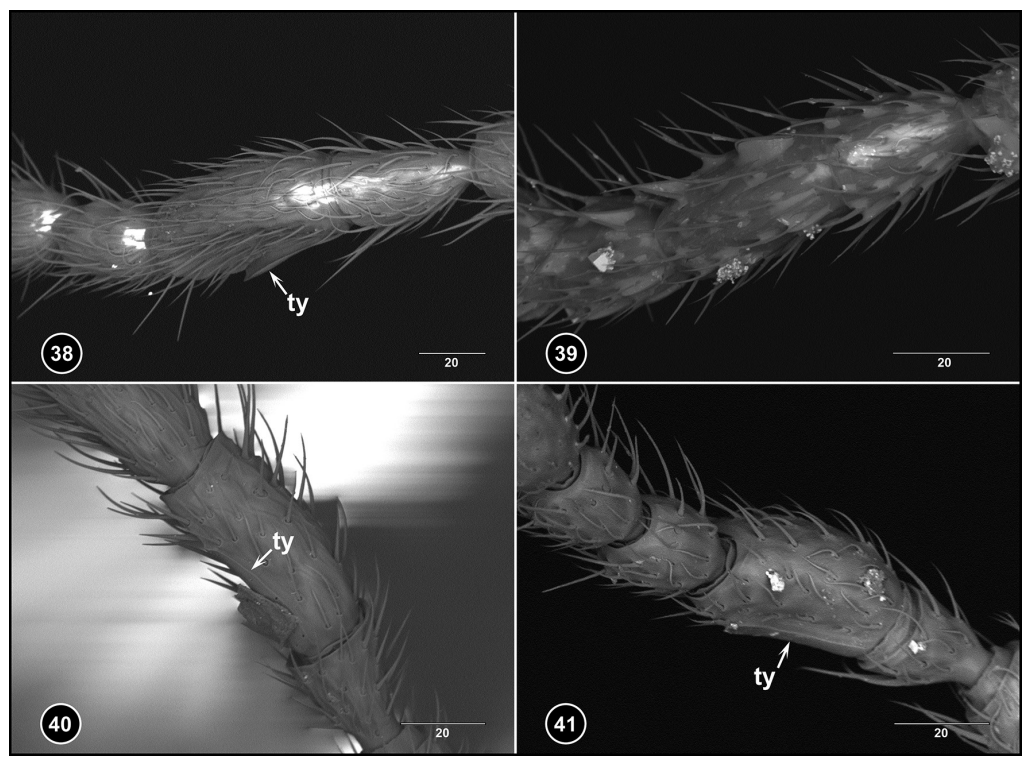

Figures 38-4 I. Tyloid morphology of male Alfredella Masner \& Huggert 38 Alfredella auriel Lahey, paratype (OSUC 698020), lateral view 39 Alfredella mephisto Lahey, paratype (OSUC 697985), lateral view (tyloid not observed) $\mathbf{4 0}$ Alfredella tasmanica Masner \& Huggert, paratype (OSUC 697978), lateral view 4 I Alfredella teres (Buhl), (OSUC 697999), lateral view. Scale bars in micrometers. 


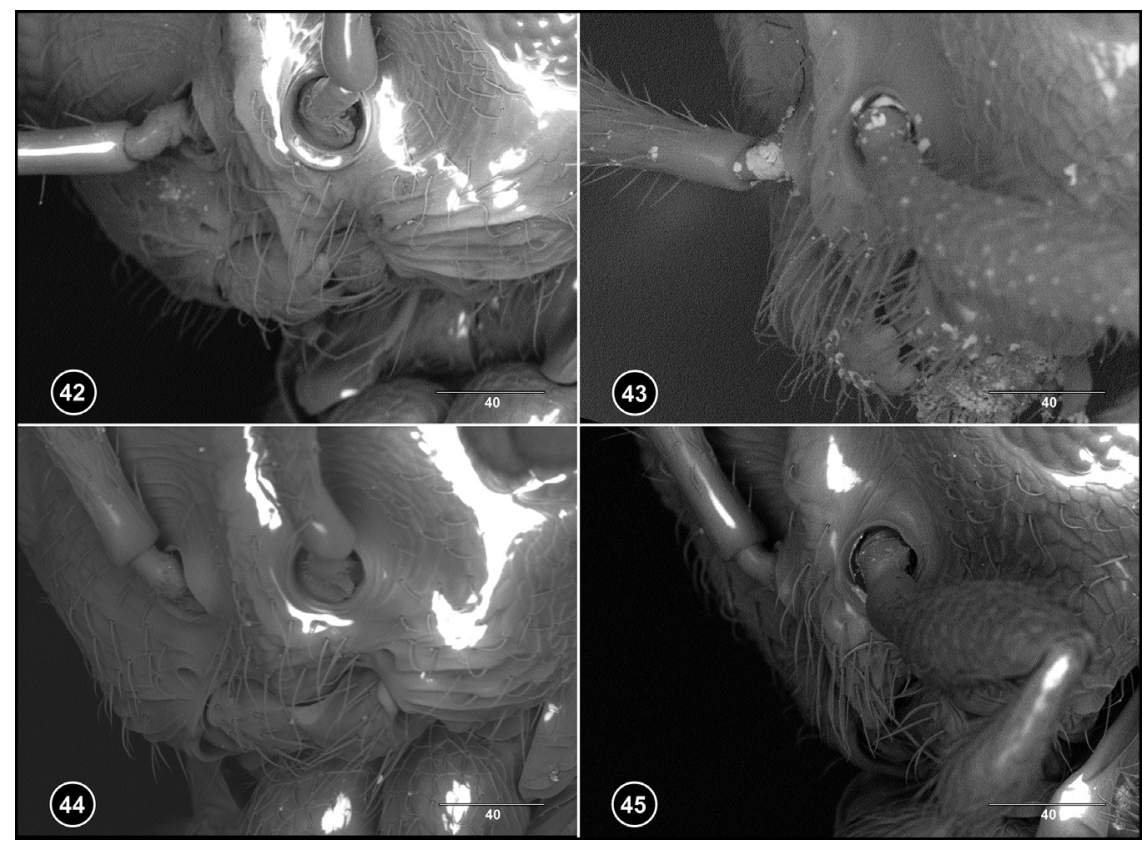

Figures 42-45. Clypeal morphology of female Alfredella Masner \& Huggert 42 Alfredella auriel Lahey, holotype (OSUC 698019), anterior view 43 Alfredella mephisto Lahey, holotype (OSUC 697984), anterolateral view 44 Alfredella tasmanica Masner \& Huggert, paratype (OSUC 697975), anterior view 45 Alfredella teres (Buhl), (OSUC 697995), anterolateral view. Scale bars in micrometers.

Diagnosis. The percurrent notauli and flattened mesoscutellum immediately separates $A l$. teres from $A l$. mephisto and $A l$. tasmanica, and the evenly setose mesoscutum and mesoscutellum distinguishes $\mathrm{Al}$. teres from $\mathrm{Al}$. auriel.

Distribution. Queensland.

Inhabited ecoregions (bioregions). Temperate Broadleaf and Mixed Forests (South Eastern Queensland).

Material examined. Holotype, female: Australia: Queensland, Mount Glorious, $27^{\circ} 19^{\prime} 54^{\prime \prime S}, 152^{\circ} 45^{\prime} 29^{\prime \prime E}$, 30.X-26.XI.1998, Malaise trap, rainforest, N. Power, Au 1581f, ZMUC 00044534 (deposited in ZMUC). Other material: Australia: $10 \mathrm{fe}-$ males, 4 males, OSUC 697993-698006, 698010 (CNCI).

Comments. Alfredella teres was originally described as a species of Amitus by Buhl (2014), who considered Al. teres to be a characteristic species of Amitus. Superficially, Al. teres is similar to Amitus: it is dorsoventrally flattened, the notauli are percurrent and widened posteriorly, and its light-yellow appendages contrast with its entirely black body. However, this species has a tubular vein in the fore wing, which excludes it from Amitus in the generic concept provided by Masner and Huggert (1989). Masner and Huggert (1989) discussed the probable presence of Amitus in Australia, drawing attention to morphological differences between the putative Australian species and those from other continents. These characters included the proximity of the lateral ocelli to the inner margin of the compound eye, the 'rim' along the posterior margin of the mesoscutellum, and similarity 


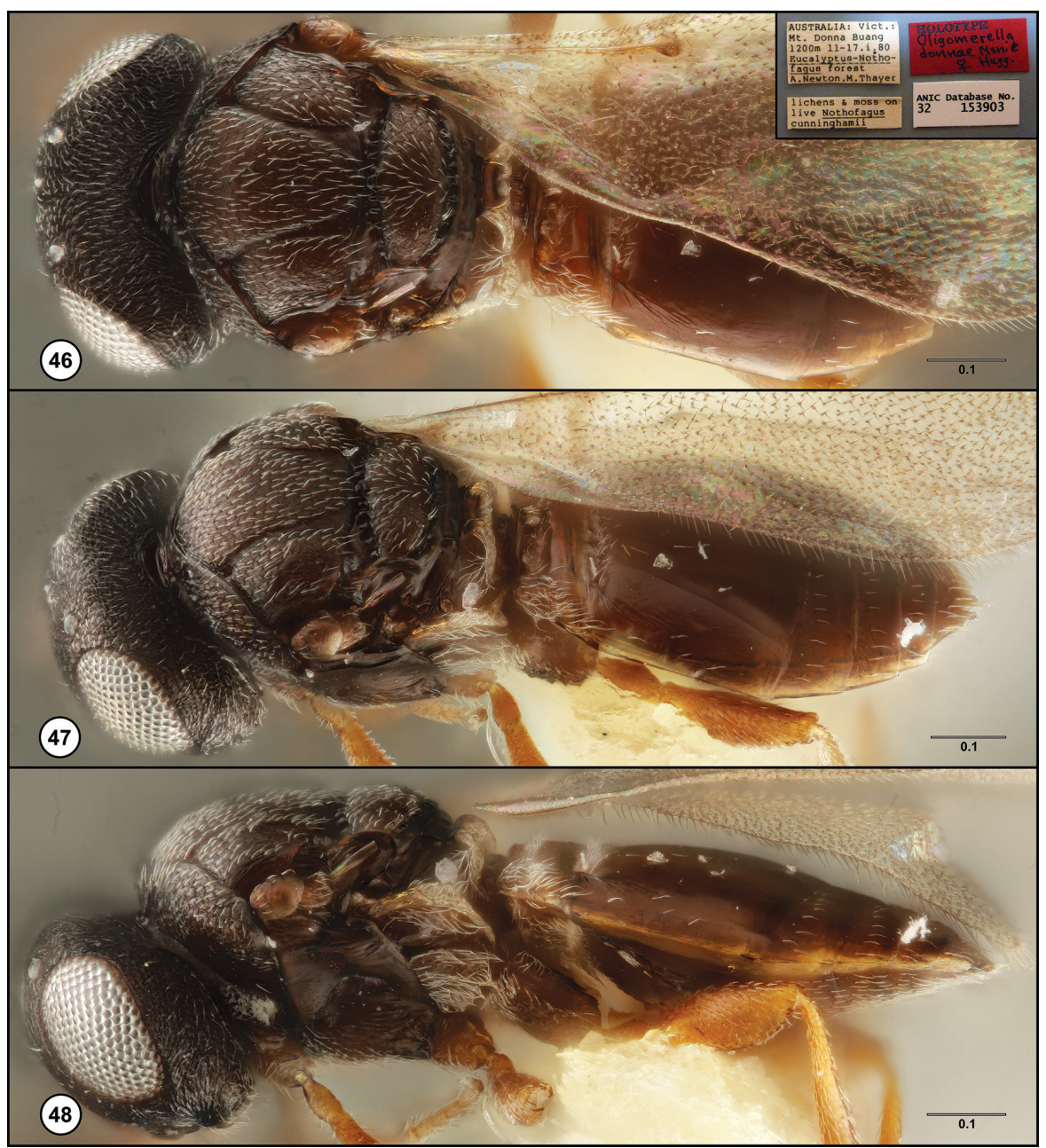

Figures 46-48. Oligomerella donnae Masner \& Huggert, female holotype (ANIC 32-153903) $\mathbf{4 6}$ head, mesosoma, metasoma, dorsal view (inset: specimen labels) $\mathbf{4 7}$ head, mesosoma, metasoma, dorsolateral view $\mathbf{4 8}$ head, mesosoma, metasoma, lateral view. Scale bars in millimeters.

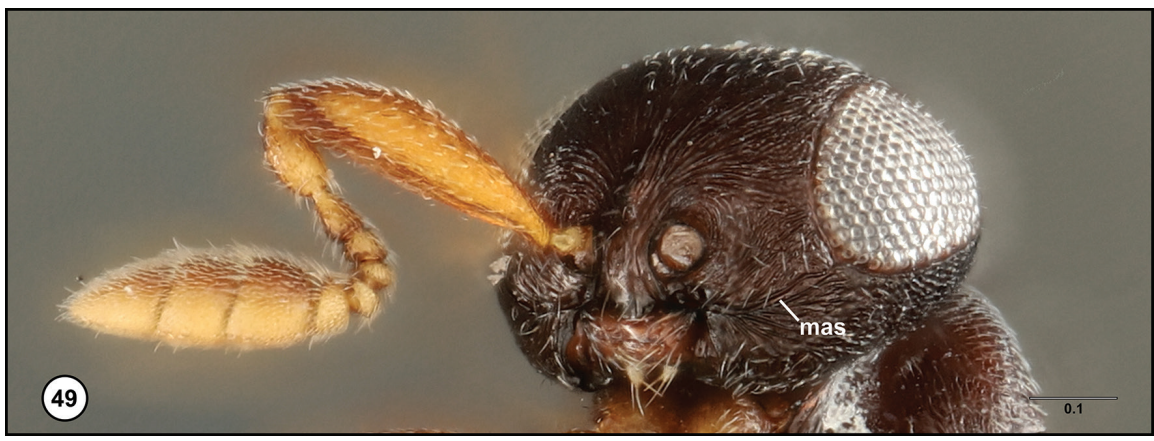

Figure 49. Oligomerella donnae Masner \& Huggert, female holotype (ANIC 32-153903), head, anteroventral view. Scale bar in millimeters. 
in the shape of the male antennae (A8-A10) and female clava. We consider the assertion by Buhl (2014) that Australian species of Amitus have a tubular vein in the fore wing to be a consequence of generic misplacement, and we find that $\mathrm{Al}$. teres fully conforms to the generic concepts of Alfredella provided here and in Masner and Huggert (1989).

\section{Synonymy of Masnerium Polaszek}

\section{Amitus Haldeman}

Amitus Haldeman, 1850: 109 (original description. Type: Amitus aleurodinus Haldeman, by monotypy); Cresson 1887: 250 (catalog of species of U.S. and Canada); Ashmead 1893: 263, 264, 292 (description, keyed); Dalla Torre 1898: 481 (cata$\log$ of species); Ashmead 1903: 97, 99 (keyed); Kieffer 1914: 361 (keyed); Kieffer 1916: 552 (description); Fouts 1924: 3, 8 (description, keyed); Kieffer 1926: 562, 697 (description, keyed, key to species); Jansson 1939: 175 (keyed); Maneval 1940: 117 (keyed); Mani 1941: 34 (catalog of species of India); Debauche 1947: 282 (taxonomic status); Muesebeck and Walkley 1951: 709 (catalog of species of U.S. and Canada); Muesebeck and Walkley 1956: 327 (citation of type species); De Santis 1967: 228 (catalog of species of Argentina); Hellén 1968: 46 (description); Kozlov 1971: 57 (keyed); Kozlov 1978: 656 (key to species of the European USSR); MacGown and Nebeker 1978: 278 (review of species of Western Hemisphere); Muesebeck 1979: 1174 (catalog of species of U.S. and Canada); Mani and Sharma 1982: 205 (description); Viggiani and Mazzone 1982: 63 (key to species of Italy); Huldén 1986: 21 (key to the species of Finland); Masner and Huggert 1989: 51 (description, species list); Vlug 1995: 15 (cataloged, catalog of world species); Kozlov 1995: 126 (keyed); Austin and Field 1997: 55, 68 (structure of ovipositor system, discussion of phylogenetic relationships); Polaszek 1997: 77 (description); Buhl 1999: 18 (key to species of Fennoscandia and Denmark); Buhl and Notton 2009: 1655 (distribution); Ghahari and Buhl 2011: 331 (species of Iran); Anjana, Rajmohana, Vimala and Sundararaj 2016: 107 (description, key to species of India).

Zacrita Förster, 1878: 46 (original description. Type: Zacrita longicornis Förster, by monotypy and original designation. Synonymized by Ashmead (1893)); Ashmead 1893: 292 (junior synonym of Amitus Haldeman); Muesebeck and Walkley 1956: 409 (citation of type species).

Elaptus Forbes, 1885: 110 (original description. Type: Elaptus aleurodis Forbes, by monotypy. Error for Alaptus Westwood. Synonymized implicitly by Ashmead (1893)); Ashmead 1893: 292 (junior synonym of Amitus Haldeman); Muesebeck and Walkley 1956: 349 (citation of type species).

Passalida Brèthes, 1914: 2 (original description. Type: Passalida spinifera Brèthes, by monotypy and original designation. Synonymized by De Santis (1941)); Muesebeck and Walkley 1956: 382 (citation of type species).

Masnerium Polaszek, 2009: 120 (original description. Type: Masnerium wellsae Polaszek, by monotypy and original designation), syn. nov. 


\section{Amitus wellsae (Polaszek), comb. nov.}

Figs $50-55,60$

Masnerium wellsae Polaszek, 2009: 121 (original description).

Comments. Polaszek (2009) established the genus Masnerium for a single male specimen reared from the whitefly Aleuroduplidens wellsae Martin (Hemiptera, Aleyrodidae, Aleyrodinae) in Australia (Martin 1999). The following combination of characters was

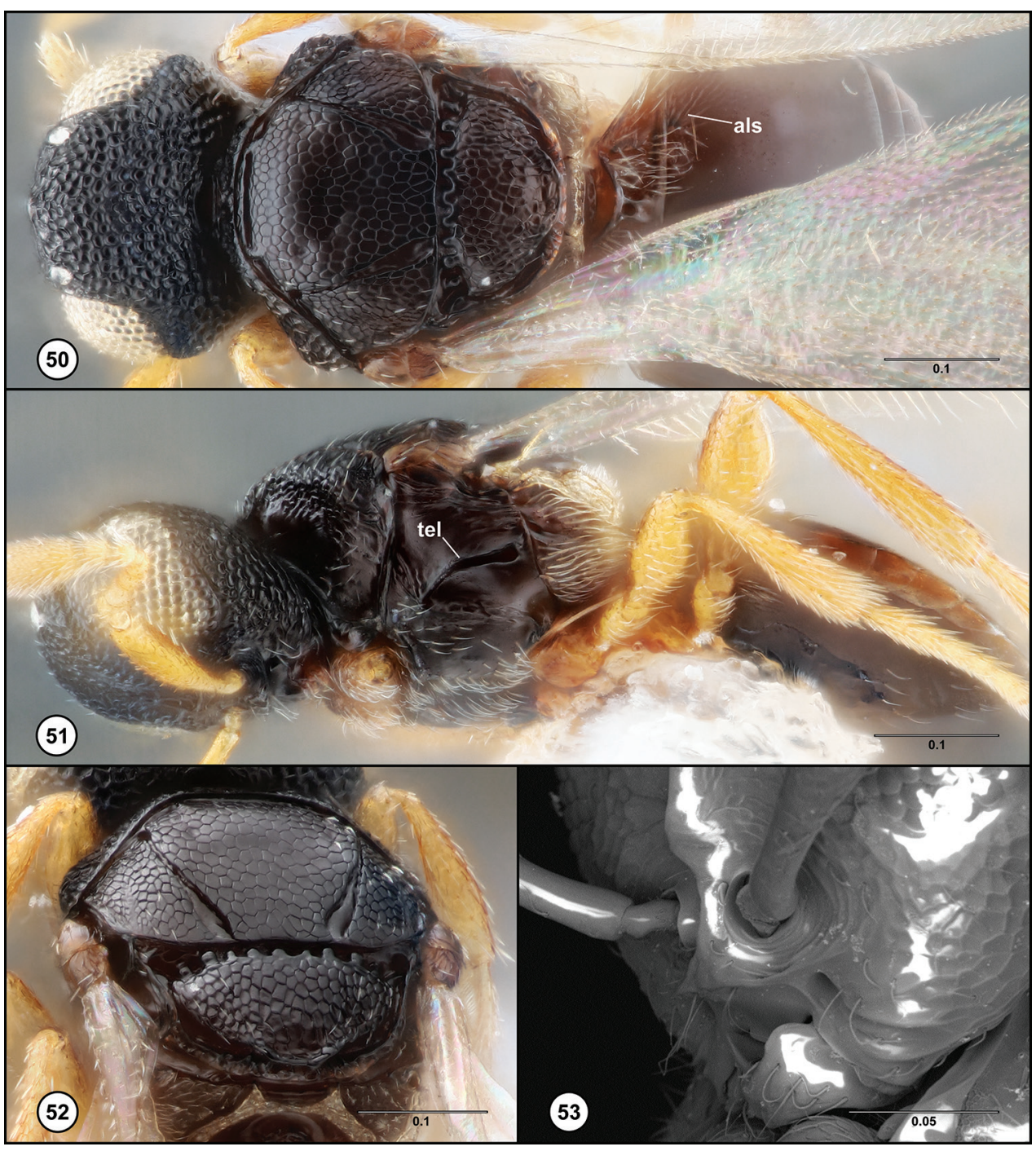

Figures 50-53. Amitus wellsae (Polaszek), female (OSUC 697974) 50 head, mesosoma, metasoma, dorsal view $\mathbf{5}$ I head, mesosoma, metasoma, lateral view $\mathbf{5 2}$ mesosoma, posterodorsal view $\mathbf{5 3}$ head, anterior view. Scale bars in millimeters. 


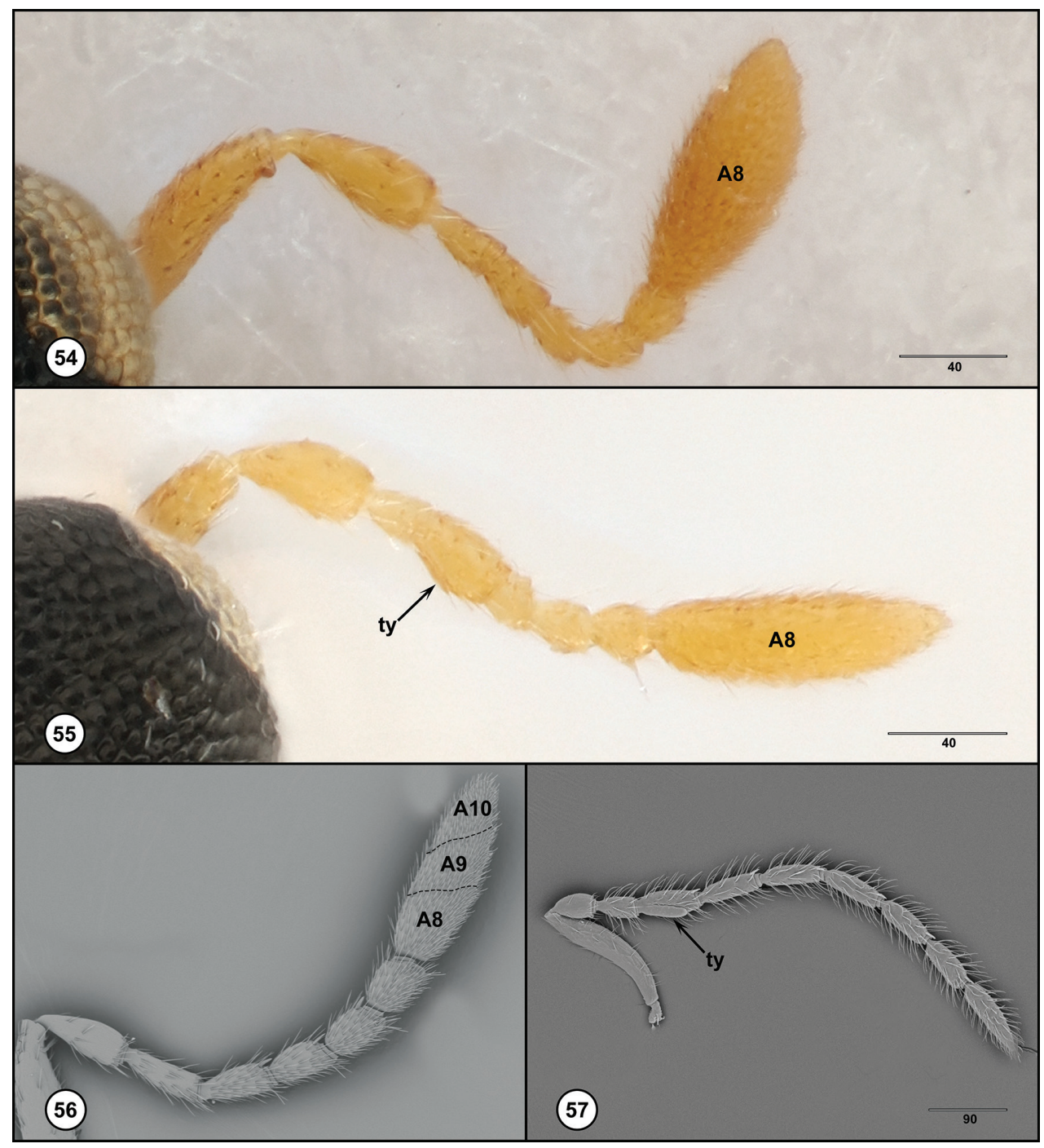

Figures 54-57. Amitus Haldeman antennal morphology 54 Amitus wellsae (Polaszek), female (NHMUK010370369), lateral view 55 Amitus wellsae (Polaszek), male (NHMUK010370506), lateral view 56 Amitus sp., female (OSUC 665643), lateral view (coated) 57 Amitus sp., male (USNMENT00989622_3), lateral view (coated). Scale bars in micrometers.

used to distinguish Masnerium from other sceliotrachelines: (1) submarginal vein of fore wing absent, (2) foamy structures on propodeum present, and (3) male antennae 8 -merous (Polaszek 2009). We posit that this character suite is not unique to Masnerium and that the taxon is best treated as a junior synonym of Amitus, a genus that was not discussed in Polaszek (2009). We base our appraisal on several character systems shared between Am. wellsae and other members of the genus, in addition to the morphology of the female, which we illustrate for the first time. 


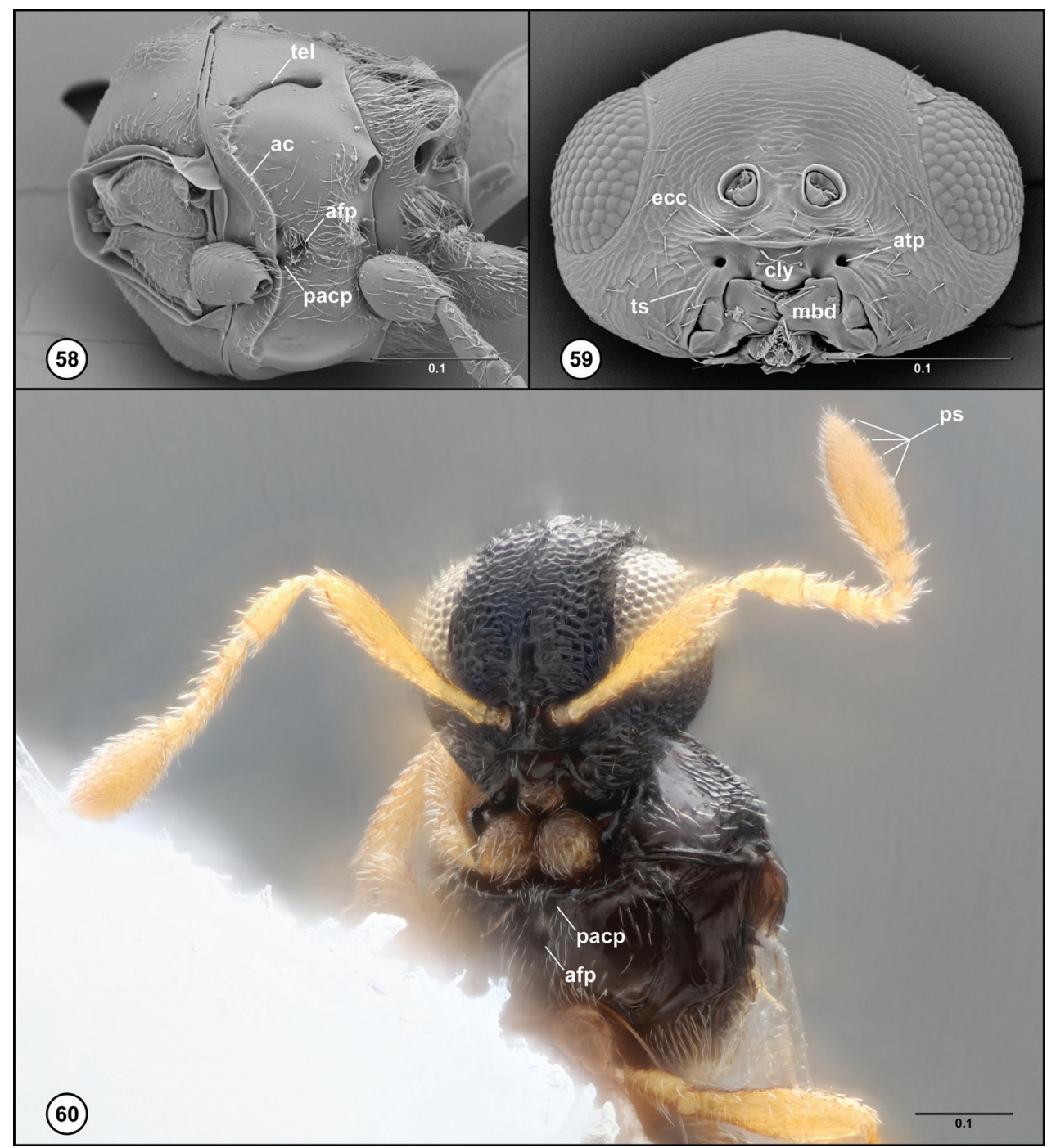

Figures 58-60. 58 Amitus sp., male (USNMENT00989622_2), mesosoma, ventral view (coated) 59 Amitus sp., male (USNMENT00989622_4), head, anterior view (coated) 60 Amitus wellsae (Polaszek), female (OSUC 697974), head and mesosoma, ventral view. Scale bars in millimeters.

\section{Character analysis.}

(1) Submarginal vein of fore wing absent. This character is a hallmark of the genus Amitus, as it was used by Haldeman (1850) to derive the genus name. No Amitus species known to us have any remnant of tracheate fore wing venation. For this reason, this character is not useful for identifying Masnerium as a lineage separate from Amitus.

(2) Foamy structures on the propodeum. The presence of this character was given inflated importance by Polaszek (2009) because the taxa with which he compared Am. wellsae, Aleyroctonus and Aphanomerus, lack foamy structures entirely. The form 


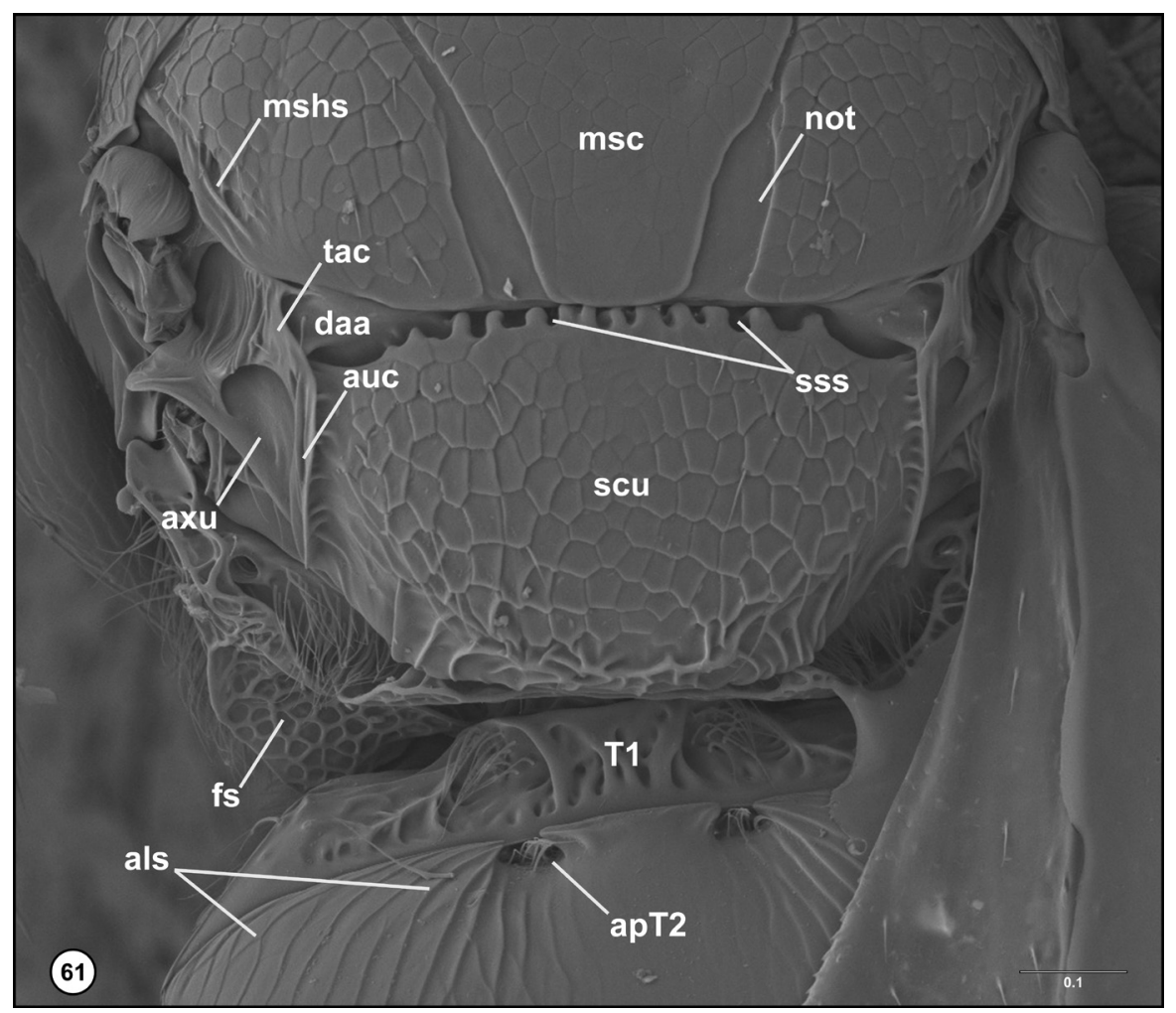

Figure 6 I. Amitus sp., male (USNMENT00989622_4), mesosoma, T1, and T2, dorsal view (coated). Scale bar in millimeters.

and distribution of foamy structures in Am. wellsae is characteristic of other members Amitus and cannot be used to separate the two genera.

(3) Male antennae 8-merous. There is a tendency of the terminal antennomeres in certain playgastroid taxa to fuse, leaving no external trace (sutures) by which to determine the original number of segments (e.g., Pseudaphanomerus Szelényi). Similarly, in certain platygastroids the male antenna has converged in form with that of the female (Talamas and Masner 2016) (e.g., Annettella gracilis Masner \& Huggert; Aphanomerella Dodd; Errolium piceum Masner \& Huggert; Helava Masner \& Huggert; Microthoron Masner; Parabaeus Kieffer; Plutomerus Masner \& Huggert; Psilanteris Kieffer; Tetrabaeus americanus (Brues)), making it difficult to distinguish between the sexes based on the antenna unless the papillary sensilla are visible or noticeable modifications have been made to the male sex-segment(s). The antenna of male Am. wellsae exhibits both types of modification: the apical antennomere (A8) lacks sutures, causing the shape of the antennal club to resemble that of the female due to the fusion of the terminal antennomeres (A8-A10). Because this has occured independently in numerous sceliotracheline genera, we do not consider it to indicate a separate genus. Rather, we refer to Masner and Huggert (1989) who put forth that this character is useful for diagnosing Australian species of Amitus. 


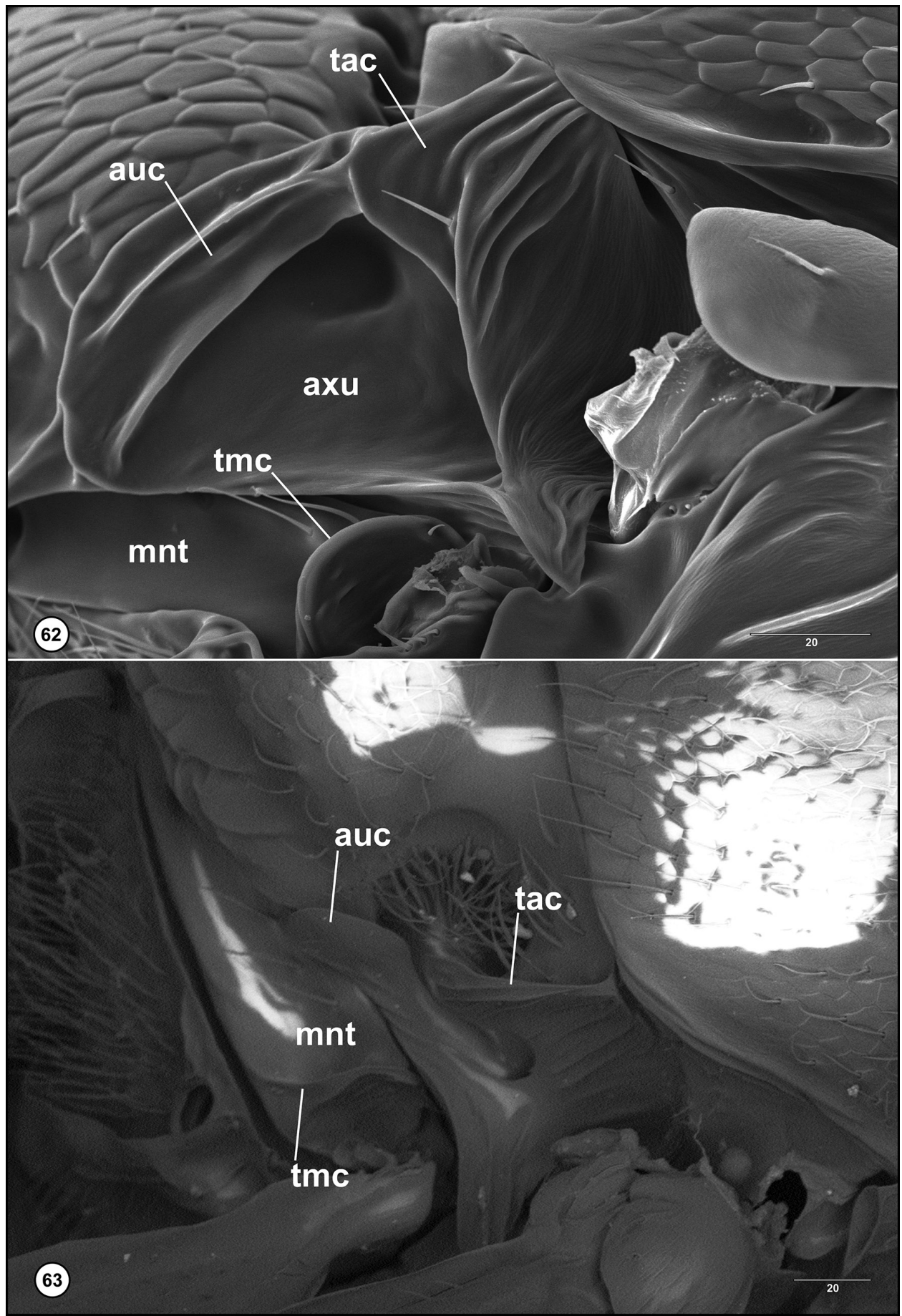

Figures 62, 63. Comparative morphology of the scutellar-axillar complex in Amitus and Alfredella 62 Amitus sp., female (OSUC 665643), lateral view (coated) 63 Alfredella mephisto Lahey, male paratype (OSUC 697985), lateral view. Scale bars in micrometers. 
(4) Number and arrangement of papillary sensilla. The number (4) and distribution (1-2-1) of papillary sensilla on the clava of Am. wellsae is characteristic of the genus.

(5) Epiclypeal carina. We coin this term to refer to the transverse carina located between the toruli and clypeus (Fig. 59). The epiclypeal carina is distinct from the epistomal sulcus because it terminates dorsal and lateral to the anterior tentorial pits. Amitus wellsae and all other species of the genus known to us possess this character, but the epiclypeal carina is not unique to Amitus. Neobia Masner \& Huggert (Sceliotrachelinae) and some species of Leptacis Förster (Platygastrinae) also have this character.

(6) Structure of the dorsal mesosoma. The dorsal mesosoma is the most significant source of characters that separates Am. wellsae from its congeners. In Am. wellsae, the anterior margin of the mesoscutum is excavated between the antero-admedian lines, and the posteromedial margin of the mesoscutellum has a distinct rim. Other members of the genus either lack the excavated region on the anteromedial mesoscutum entirely or it is incomplete. Likewise, the posterior margin of the mesoscutellum lacks a defined rim in the non-Australian species of the genus. Most importantly, however, the transaxillar and axillular carinae are fused in Am. wellsae, a diagnostic character for Amitus (Figs 1, 62).

(7) Structure of the lateral mesosoma. The morphology of the lateral mesosoma was not treated by Polaszek (2009) due to the mounting method. The structure of the lateral mesosoma in Am. wellsae is representative of the genus. The netrion is clearly indicated, the transepisternal line terminates in anterior and posterior pits, the acetabular carina is visible at the anteroventral edge of the mesopleuron, and the sculpture of the metapleural carina is foamy (Fig. 51).

\section{Acknowledgements}

We thank S. Hemly and L. Musetti (OSUC) for critical assistance with specimen handling and databasing. Images of the Alfredella teres holotype were provided by Lars Vilhelmsen and Mikkel Høegh Post (The Natural History Museum of Denmark). We are indebted to Jonathan Bremer (Florida State Collection of Arthropods, Gainesville, Florida) for taking the scanning electron micrographs. Dr. Andrew Polaszek (The Natural History Museum, London, UK), Dr. Susan Halbert, and Jonathan Bremer (Florida State Collection of Arthropods, Gainesville, Florida) provided useful feedback on a draft of the manuscript. We thank the Florida Department of Agriculture and Consumer Services - Division of Plant Industry for their support on this contribution.

\section{References}

Anjana M, Rajmohana K, Vimala D, Sundaraj R (2016) On a new species of Amitus Haldeman (Hymenoptera: Platygastridae) parasitizing whitefly Zaphanera sp. (Aleyrodidae) on Vigna trilobata from India. Halteres 7: 106-111. 
Ashmead WH (1893) A monograph of the North American Proctotrypidae. Bulletin of the United States National Museum 45: 1-472. https://doi.org/10.5479/si.03629236.45.1

Ashmead WH (1903) Classification of the pointed-tailed wasps, or the superfamily Proctotrypoidea. - III. Journal of the New York Entomological Society 11: 86-99. https://www. jstor.org/stable/25003029

Austin AD, Field SA (1997) The ovipositor system of scelionid and platygastrid wasps (Hymenoptera: Platygastroidea): comparative morphology and phylogenetic implications. Invertebrate Taxonomy 11: 1-87. https://doi.org/10.1071/IT95048

Bin F (1981) Definition of female antennal clava based on its plate sensilla in Hymenoptera Scelionidae Telenominae. Redia 64: 245-261.

Brèthes J (1914) Les ennemis de la "Diaspis pentagona" dans la Republique Argentine. Nunquam Otiosus 1: 1-16.

Buhl PN (1999) A synopsis of the Platygastridae of Fennoscandia and Denmark (Hymenoptera, Platygastroidea). Entomofauna, Zeitschrift für Entomologie 20: 17-52.

Buhl PN (2014) New species of Platygastrinae and Sceliotrachelinae (Hymenoptera, Platygastroidea: Platygastridae) from Australia. International Journal of Environmental Studies 71: 425-448. https://doi.org/10.1080/00207233.2014.939436

Buhl PN, Notton DG (2009) A revised catalogue of the Platygastridae of the British Isles (Hymenoptera: Platygastroidea). Journal of Natural History 43: 1651-1703. https://doi. org/10.1080/00222930902993732

Cresson E (1887) Synopsis of the Families and Genera of the Hymenoptera of America, North of Mexico, Together with a Catalogue of the Described Species, and Bibliography. Transactions of the American Entomological Society and Proceedings of the Entomological Section of the Academy of Natural Sciences, Supplementary Volume. https://doi. org/10.2307/25076494

Dalla Torre CG (1898) Catalogus hymenopterorum hucusque descriptiorum systematicus et synonymicus. Vol. V: Chalcididae et Proctotrupidae. Sumptibus Guilelmi Engelmann: Lipsiae.

Debauche HR (1947) Scelionidae de la faune belge (Hymenoptera Parasitica). Bulletin et Annales de la Société Entomologique de Belge 83: 255-285.

De Santis L (1967) Catálogo de los himenópteros argentinos de la serie parasitica, incluyendo Bethyloidea. Com. Inv. Cient., Pcia Buenos Aires Gob., La Plata, 337 pp.

Forbes SA (1885) Fourteenth report of the State Entomologist on the noxious and beneficial insects of the State of Illinois. H. W. Rokker, State Printer and Binder, Springfield, $136 \mathrm{pp}$.

Förster A (1878) Kleine Monographien parasitischer Hymenopteren. Verhandlungen des Naturhistorischen Vereines de Preussischen Rheinlande und Westfalens 35: 42-82.

Fouts RM (1924) Revision of the North American wasps of the subfamily Platygasterinae. Proceedings of the United States National Museum 63: 1-145. https://doi.org/10.5479/ si.00963801.63-2484.1

Ghahari H, Buhl PN (2011) Check-list of Iranian Platygastridae (Hymenoptera, Platygastridae). Entomofauna, Zeitschrift für Entomologie 32: 329-336. 
Haldeman SS (1850) On four new species of Hemiptera of the genera Ploiaria, Chermes, and Aleurodes, and two new Hymenoptera, parasitic in the last named genus. The American Journal of Science 59: 108-111.

Hellén W (1968) Platygasterinenfunde aus Finnland (Hymenoptera, Proctotrupoidea). Notulae Entomologicae 48: 45-48.

Huldén L (1986) The whiteflies (Homoptera, Aleyrodoidea) and their parasites in Finland. Notulae Entomologicae 66: 1-40.

Jansson A (1939) Studier över svenska proctotrupider. I. För faunan nya släkten. Entomologisk Tidskrift 60: 155-175.

Kieffer JJ (1914) Proctotrypidae ( $3^{\mathrm{e}}$ partie). Species des Hyménoptères d'Europe et d'Algérie 11: 305-448.

Kieffer JJ (1916) Beitrag zur Kenntnis der Platygasterinae und ihrer Lebensweise. Centralblatt fur Bakteriologie, Parasitenkunde und Infektionskrankheiten 46: 547-592.

Kieffer JJ (1926) Scelionidae. Das Tierreich (Vol. 48). Walter de Gruyter \& Co., Berlin, 885 pp.

Kozlov MA (1971) Proctotrupoids (Hymenoptera, Proctotrupoidea) of the USSR. Trudy Vsesoyuznogo Entomologicheskogo Obshchestva 54: 3-67.

Kozlov MA (1978) Superfamily Proctotrupoidea. In: Medvedev GS (Ed.) Determination of insects of the European portion of the USSR (Vol. 3, Part 2). Nauka, Leningrad, 538-664.

Kozlov MA (1995) 26. Fam. Platygastridae. In: Lehr PA (Ed.) Key to insects of Russian Far East in six volume (Vol. 4). Neuropteroidea, Mecoptera, Hymenoptera. Part 2. Hymenoptera. Dal'nauka, Vladivostok, 121-127.

Lahey Z, Masner L, Johnson NF (2019a) Calixomeria, a new genus of Sceliotrachelinae (Hymenoptera, Platygastridae) from Australia. ZooKeys 830: 63-73. https://doi.org/10.3897/ zookeys.830.32463

Lahey Z, Masner L, Johnson NF, Polaszek A (2019b) Revision of Aleyroctonus Masner \& Huggert (Hymenoptera, Platygastridae, Sceliotrachelinae). In: Talamas E (Ed.) Advances in the Systematics of Platygastroidea II. Journal of Hymenoptera Research 73: 73-93. https:// doi.org/10.3897/jhr.73.38383

Lahey Z, van Noort S, Polaszek A, Masner L, Johnson NF (2019c) Revision of the Afrotropical genus Pulchrisolia Szabó (Hymenoptera, Platygastridae, Sceliotrachelinae). In: Talamas E (Ed.) Advances in the Systematics of Platygastroidea II. Journal of Hymenoptera Research 73: 39-71. https://doi.org/10.3897/jhr.73.33876

MacGown MW, Nebeker TE (1978) Taxonomic review of Amitus (Hymenoptera: Proctotrupoidea: Platygastridae) of the Western Hemisphere. The Canadian Entomologist 110: 275-283. https://doi.org/10.4039/Ent110275-3

Maneval H (1940) Fam. XVII. Proctotrypides. La Faune de la France en tableaux synoptiques illustres. Tome VII. Hymenopteres par Lucien Berland avec la collaboration de MM. Raymond Benoit, Francis Bernard, Henri Maneval. XVII. 93-118.

Mani MS (1941) Serphoidea. Catalogue of Indian Insects 26: 1-60.

Mani MS, Sharma SK (1982) Proctotrupoidea (Hymenoptera) from India. A review. Oriental Insects 16: 135-258. https://doi.org/10.1080/00305316.1982.10434314 
Martin JH (1999) The whitefly fauna of Australia (Sternorrhyncha: Aleyrodidae): a taxonomic account and identification guide. CSIRO Entomology Technical Paper No. 38.

Masner L (1980) Key to genera of Scelionidae of the Holarctic region, with descriptions of new genera and species (Hymenoptera: Proctotrupoidea). Memoirs of the Entomological Society of Canada 113: 1-54. https://doi.org/10.4039/entm112113fv

Masner L, Huggert L (1989) World review and keys to genera of the subfamily Inostemmatinae with reassignment of the taxa to the Platygastrinae and Sceliotrachelinae (Hymenoptera: Platygastridae). Memoirs of the Entomological Society of Canada 147: 1-214. https://doi. org/10.4039/entm121147fv

Mikó I, Vilhelmsen L, Johnson NF, Masner L, Pénzes Z (2007) Skeletomusculature of Scelionidae (Hymenoptera: Platygastroidea): head and mesosoma. Zootaxa 1571: 1-78. https:// doi.org/10.11646/zootaxa.1571.1

Muesebeck CFW, Walkley LM (1951) Superfamily Proctotrupoidea. Hymenoptera of America north of Mexico - Synoptic Catalog. United State Department of Agriculture Monograph 2: 655-718.

Muesebeck CFW, Walkley LM (1956) Type species of the genera and subgenera of parasitic wasps comprising the superfamily Proctotrupoidea (order Hymenoptera). Proceedings of the United States National Museum 105: 319-419. https://doi.org/10.5479/ si.00963801.3359.319

Muesebeck CFW (1979) Superfamily Proctotrupoidea. In: Krombein K, Hurd P, Smith D, Burks B (Eds) Catalog of Hymenoptera in America north of Mexico (Vol. 1). Symphyta and Apocrita (Parasitica). Smithsonian Institution Press, Washington DC, 1121-1186.

Polaszek A (1997) Amitus Haldeman (Hymenoptera: Platygasteridae): a genus of whitefly parasitoids new to Britain. Entomologist's Monthly Magazine 133: 77-79.

Polaszek A (2009) Masnerium wellsae gen. n., sp. n. (Hymenoptera, Platygastridae, Sceliotrachelinae) a parasitoid of Aleuroduplidens wellsae Martin (Hemiptera, Aleyrodidae) in Australia. ZooKeys 20: 119-125. https://doi.org/10.3897/zookeys.20.189

Shorthouse DP (2010) SimpleMappr, an online tool to produce publication-quality point maps. [Retrieved from] https://www.simplemappr.net [Accessed September 04, 2020]

Talamas EJ, Masner L (2016) Revision of New World Helava Masner \& Huggert (Platygastridae, Sceliotrachelinae). Journal of Hymenoptera Research 53: 1-24. https://doi. org/10.3897/jhr.53.10217

Talamas EJ, Johnson NF, Buffington ML, Dong R (2016) Archaeoteleia Masner in the Cretaceous and a new species of Proteroscelio Brues (Hymenoptera, Platygastroidea). In: Talamas EJ, Buffington ML (Eds) Advances in the Systematics of Platygastroidea. Journal of Hymenoptera Research 56: 241-261. https://doi.org/10.3897/jhr.56.10388

Thackway R, Cresswell ID (1995) An Interim Biogeographic Regionalisation for Australia: a framework for establishing the national system of reserves, Version 4.0. Australian Nature Conservation Agency, Canberra.

Viggiani G, Mazzone P (1982) The Amitus Hald. (Hym. Platygastridae) of Italy, with descriptions of three new species. Bollettino del Laboratorio di Entomologia Agraria "Filippo Silvestri” Portici 39: 59-69. 
Vlug HJ (1995) Catalogue of the Platygastridae (Platygastroidea) of the world (Insecta: Hymenoptera). Hymenopterorum Catalogus 19: 1-168. https://doi.org/10.5281/zenodo.24358

Yang SY, Zhong YZ, Zhang JP, Wang XP, Zhang F (2016) A comparative scanning electron microscopy study on antennal sensilla of Trissolcus japonicus and Trissolcus plautiae, egg parasitoids of stink bugs (Pentatomidae). Annals of the Entomological Society of America 109: 112-120. https://doi.org/10.1093/aesa/sav104

Yoder MJ, Mikó I, Seltmann K, Bertone MA, Deans AR (2010) A gross anatomy ontology for Hymenoptera. PLoS ONE 5(12): e15991. https://doi.org/10.1371/journal.pone.0015991

\section{Supplementary material I}

\section{Revision of the Australian genus Alfredella Masner \& Huggert}

Authors: Zachary Lahey, Elijah Talamas, Lubomír Masner, Norman F. Johnson

Data type: Morphological terminology

Explanation note: List and definitions of morphological terms used in a Revision of the Australian genus Alfredella Masner \& Huggert (Hymenoptera, Platygastridae, Sceliotrachelinae).

Copyright notice: This dataset is made available under the Open Database License (http://opendatacommons.org/licenses/odbl/1.0/). The Open Database License $(\mathrm{ODbL})$ is a license agreement intended to allow users to freely share, modify, and use this Dataset while maintaining this same freedom for others, provided that the original source and author(s) are credited.

Link: https://doi.org/10.3897/jhr.87.58368.suppl1 